\title{
Research Paper \\ Emotional charactristics of personality, cognitive problems, emotional regulation strategies and marital adjustment: a comparative study in women with high and low fear of infidility
}
Seyed Saeid Purnaghash Tehrani ${ }^{1}$, Somayeh Ghasemi Morodi ${ }^{2}$, Seyed MohammadReza Rezazadeh ${ }^{3}$
1. Associate Professor, Department of Psychology, University of Tehran, Tehran, Iran.
2. M.A in Clinical Psychology, Department of Clinical Psychology, University of Tehran, Tehran, Iran.
3. Assistant Professor, Faculty of Psychology and Educational Sciences, University of Tehran, Tehran, Iran.

Citation: Purnaghash Tehrani S.S, Ghasemi Morodi S, Rezazadeh S.M.R. Emotional charactristics of personality, cognitive problems, emotional regulation strategies and marital adjustment: a comparative study in women with high and low fear of infidility. J of Psychological Science. 2021; 20(104): 1313-1329.

URL: https://psychologicalscience.ir/article-1-1142-fa.html
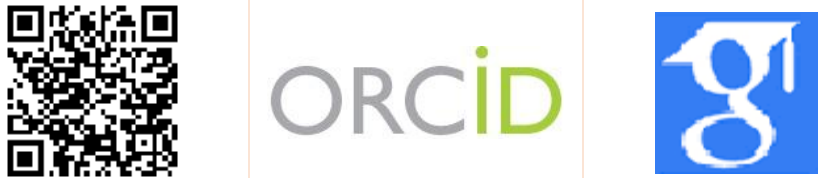

$\underline{10.52547 / J P S .20 .104 .1313}$

\section{A R T I C L E I N F O A B S T R A C T}

\section{Keywords:}

Emotional

Characteristics

personality,

Cognitive problems,

cognitive strategies of

emotion regulation,

marital adjustment,

Fear of Infidelity

Received: 06 Feb 2021

Accepted: 27 Feb 2021

Available: 23 Oct 2021
Background: Despite the complexities and high prevalence of marital infidelity and its detrimental consequences in addition to its emotional load in marital relationships, particularly in women, not much research has been conducted because the taboo nature of this issue.

Aims: As such, the purpose of this study was to compare the emotional characteristics of personality, cognitive problems, emotional regulation strategies and marital adjustment in women with high fear and low fear of marital infidelity.

Methods: The present research is a causal comparative research. The sample consists of 89 women from the city of Karaj who referred to counseling centers for marital problems and met the entry and exit criteria and agreed to participate in the study and were selected by available method. The research instrument consisted of the Montreal Cognitive Function Questionnaire, the Emotional Characteristics of Cloninger Personality Questionnaire, the Emotional Regulation Questionnaire (ERQ), the Marital Adjustment Scale (DAS), and a single question assessing fear of infidelity based on a 9-degree likert type. Data were analyzed by SPSS 23 software and factor analysis using independent t-test and non-parametric Mann-Whitney test.

Results: There was a significant difference between emotional characteristics of personality, the rate of re-evaluation strategy and the degree of marital adjustment of women with high fear and low fear of marital infidelity $(\mathrm{P}<0.05)$. Also, there was no significant difference between cognitive performance and emotional rejection strategies in women with high fear and low fear of marital infidelity $(\mathrm{P}>0.05)$.

Conclusion: Given the present findings with differences in variables in two groups of women with high and low fear of infidelity, it can have practical implications for family and couple councilors.

* Corresponding Author: Seyed Saeid Purnaghash Tehrani, Associate Professor, Faculty of Psychology and Educational Sciences, University of Tehran, Tehran, Iran.

E-mail: Spnaghash@ut.ac.ir

Tel: (+98) 9122074388

2476-5740/ (C) 2021 The Authors. This is an open access article under the CC BY-NC-ND license

(https://creativecommons.org/licenses/by-nc/4.0/). 


\section{Extended Abstract}

\section{Introduction}

The family is one of the most important social systems that is formed based on marriage between two people of the opposite sex. Maintaining and maintaining a family is very important. The family as a social unit is the center of growth and development, healing and healing and change and transformation of injuries and complications, which is both the bedrock of prosperity and the bedrock of the relations between its members (Shoaa Kazemi \& Seif, 2010). Marital relationships are the most basic and important interpersonal relationships that provide the basic structure for establishing family relationships and raising children (Berger \& et al., 2013). One of the harms of married life is marital infidelity, which is the most important threat to the performance, stability and continuity of marital relationships. (Mark, Janssen \& Milhausen, 2011).

Marital infidelity, according to a general definition, is a violation of the commitment of a two-person relationship, which leads to the formation of some degree of emotional and physical intimacy with someone outside the relationship (Aviram \& Amichai-Hamburger, 2005). Although marital infidelity is a common concept in marriage, it is little known and due to the taboo nature of the issue, there is no clear background and study on this issue (Shackelford, Besser \& Goetz, 2008). Severe emotional distress after exposing marital infidelity is often accompanied by cognitive disturbance. One of the major disorders experienced by an unfaithful spouse is severe rumination about the event, which can be so severe and uncontrollable that it interferes with a person's daily functioning and concentration (Brown, 2001). Another important cognitive response that is expressed when discovering an extramarital affair is a change in a person's beliefs about his or her spouse and relationship with him or her. One can no longer trust and feel secure in one's spouse (Spring \& Spring, 1996).

According to the results of a qualitative study conducted in Iran, it was found that two underlying and main factors are involved in the emergence of signs of women's fear of infidelity. These two factors were: the theme of women's internal fear factors (originated from: 1-Feeling of inferiority 2- Fear of returning to difficult past situations); and the theme of increasing and promoting a culture of marital infidelity in society. (BabaNori, 2017).

Thus, infidelity and consequently fear of infidelity can cause a wide range of problems in spouses. As mentioned, confusion in cognitive function is one of the consequences. The term cognition refers to the internal mental processes or the ways in which information is processed, that is, the ways in which we perceive information, recognize it, encode it, store it in memory, and whenever We need to call them from memory and use them; In other words, through cognitive processes, man knows the world around him, becomes aware of them and responds to them (Moradi, 2015). Cognitive functions refer to an individual's ability to process thoughts, and the most important cognitive domains in neuropsychological assessments include intelligence, memory, attention, working memory, executive functions, perception, language, and information processing speed. Be (Ray, Kesel \& Augostina, 2009 quoted by Badie, 2011). Quality of life studies have reported a direct relationship between poor cognitive function and reduced quality of life (Verbaan \& et al., 2007). Also, in various studies, different results of the effects of depression and anxiety on cognitive function have been expressed (Rock \& et al., 2014; Badrio, 2009). As mentioned, betrayed women and those who are afraid of betrayal face a lot of anxiety and this can affect their cognitive function. Emotion plays an important role in various aspects of life such as adapting to life changes and stressful events. Emotions are of a high quality in that they can provoke a positive or negative reaction in people. If they are appropriate to the situation, it will cause a positive reaction, otherwise it will cause a negative reaction. Therefore, when emotions become intense or prolonged or are not compatible with the situation, then it is necessary to regulate them (Gross, 1998). People have been shown to use different emotion regulation strategies to modify or modify their emotional experience in the face of stressful events (Aldao, Nolen-Hoeksema \& Schweizer, 2010). 


\section{Monthly Journal of Psychological Science}

People who fall victim to infidelity experience intense and varied emotions and may act differently in regulating those emotions. According to research background, one of the influential variables on emotion regulation is couple relationships. Impairment of emotional regulation and marital turmoil at the individual and couple level have an interactive relationship with each other. In fact, how couples regulate emotion in the etiology of confusion and individual pathology is effective in the continuation of confusion and disorder, recurrence or maintenance of therapeutic progress and prognosis of treatment (Snyder \& et al., 2006). Thus, marital infidelity can lead to dysfunction of emotion regulation in individuals. In this regard, Behdoust (2016) in his research showed that emotion regulation styles are different in betrayed women and ordinary women.

Numerous terms such as satisfaction, compromise, satisfaction, success and marital quality have been used to describe marital compatibility. Usually the quality of adjustment and marital satisfaction are used interchangeably (Mutlu \& et al., 2018). Marital satisfaction is defined as having a spirit of trust and mutual attention, a sense of overall relationship happiness, mutual respect and support, and stability in marriage (Jackson \& et al., 2014). Ellis defines marital satisfaction in the objective feeling of satisfaction, satisfaction and pleasure of the couple from all their relationships. Sexual pornography seems to have a negative effect on love and marital satisfaction. Sexual infidelity for people of all ages is one of the main reasons for breaking the rules of marriage and commitment (Shepard, Nelson \& Androly Matti, 1995), which strongly affects the performance and stability of the relationship; Breaks the rules of the relationship and goes against the expectations of the other party (Drigotas \& et al, 1999; Wiseman, Dixon \& Johnson, 1997).

Considering the importance of infidelity and its effects on the quality of marital life, and the few studies conducted in Iran in the present study, we intend to address the issue of whether between emotional characteristics of personality and cognitive function and cognitive emotion regulation strategies and adaptation. Marriage is there a difference
Vol. 20, No. 104, Autumn(November) 2021

between women who are more afraid of marital infidelity and women who are less afraid?

\section{Method}

The present research is applied research in terms of purpose and comparative causal research in terms of method. The study population consisted of all married women in Karaj who referred to one of the counseling centers in the spring and summer of 2018 due to marital problems. 89 women were selected by the available method according to the entry and exit criteria and after obtaining consent. Inclusion criteria, being married, answering the 9-point assessment scale to determine the fear of marital infidelity, willingness to participate in research and completing questionnaires. Exclusion criteria also include unwillingness to continue research and providing incomplete information. In order to reduce the resistance under the heading of fear of betrayal during the conversation, the necessary explanations were provided to the participants and they were informed that there is no need to mention their names in the questionnaires. After obtaining verbal consent from participants by the Montreal Cognitive Functioning Questionnaire (MoCA), Cloninger Personality Emotional Characteristics Questionnaire, Cognitive Emotion Regulation Questionnaire (ERQ), Marital Adjustment Scale (DAS), and a 9-point researchermade assessment scale of fear of infidelity the data were analyzed by SPSS-23 software and factor analysis using independent t-test and non-parametric Uman-Whitney test.

\section{Results}

Examination of demographic information showed that all subjects were women and the average age of the subjects was 34.56 , with the youngest 23 years old and the oldest 59 years old. $48.3 \%$ (43 people) of the research sample have less than bachelor's degree, $40.4 \%$ (36 people) have a bachelor's degree and $11.2 \%$ (10 people) have a master's degree. $89.9 \%$ of the sample (80 people) are married once and $10.1 \%$ (9 people) have been married twice. $10.1 \%$ have no children, $52.8 \%$ have one child, $29.2 \%$ have two children, $6.7 \%$ have three children and $1.1 \%$ have four children from their first marriage. Of the 9 people who had a second marriage, 8 have no children 


\section{Monthly Journal of Psychological Science}

and 1 has a child from the second marriage. 30.3\% (27 people) are self-employed, 36\% (30 people) are government employees and 36\% (32 people) are unemployed.

In order to calculate the scores of cognitive function questionnaires, emotional characteristics, reevaluation strategy, emotional inhibition strategy and marital adjustment of the subjects, we calculated the scores using factor analysis. Then, we classified people with a fear of marital infidelity score of more
Vol. 20, No. 104, Autumn(November) 2021

than five in the group of women with high fear, and people with a score below five in the group of low fear. In order to use appropriate parametric or nonparametric tests, we first examined the hypothesis that the scores obtained in the two groups of high fear and low fear were normal, and if the scores were normal, the T-test was independent of the two communities and in If the normal assumption is not established, we used the non-parametric MannWhitney test.

Table 1. Normality test results and mean variables

\begin{tabular}{ccccc}
\hline Variable & Fear of Infidility & Mean & K-S statistics & $\mathrm{P}$ \\
\hline \multirow{2}{*}{ Cognitive function } & Low fear & $27 / 442$ & $0 / 206$ & $0 / 00$ \\
& High fear & $27 / 476$ & $0 / 22$ & $0 / 009$ \\
Emotional features & Low fear & $31 / 839$ & $0 / 062$ & $0 / 20$ \\
& High fear & $28 / 086$ & $0 / 132$ & $0 / 20$ \\
\multirow{3}{*}{ Reassessment strategy } & Low fear & $16 / 81$ & $0 / 66$ & $0 / 20$ \\
& High fear & $14 / 19$ & $0 / 149$ & $0 / 20$ \\
Emotional Inhibition str & Low fear & $8 / 867$ & $0 / 061$ & $0 / 20$ \\
& High fear & $8 / 244$ & $0 / 187$ & $0 / 054$ \\
Marital compatibility & Low fear & $75 / 417$ & $0 / 161$ & $0 / 00$ \\
& High fear & $46 / 539$ & $0 / 207$ & $0 / 207$ \\
\hline
\end{tabular}

Table 2. Mann-Whitney test results

\begin{tabular}{|c|c|c|c|c|}
\hline Variable & \multicolumn{2}{|c|}{ Marital compatibility } & \multicolumn{2}{|c|}{ Cognitive function } \\
\hline $\begin{array}{c}\text { Mann-Whitney } \\
\text { Z statistics } \\
\text { P }\end{array}$ & $\begin{array}{c}201 \\
-4 / 957 \\
0 / 00\end{array}$ & & $\begin{array}{c}697 / 500 \\
-0 / 165 \\
0 / 869 \\
\end{array}$ & \\
\hline$\frac{\text { Table 3. Norma }}{\text { Variable }}$ & $\begin{array}{l}\text { t results and meal } \\
\text { Fear of Infidility }\end{array}$ & $\frac{\text { bscale }}{\text { Mean }}$ & $\frac{\text { motional char }}{\text { K-S statistics }}$ & $\mathrm{P}$ \\
\hline Novelty seeking & $\begin{array}{l}\text { Low fear } \\
\text { High fear }\end{array}$ & $\begin{array}{l}13 / 693 \\
13 / 282\end{array}$ & $\begin{array}{l}0 / 078 \\
0 / 133\end{array}$ & $\begin{array}{l}0 / 20 \\
0 / 20\end{array}$ \\
\hline Perseverance & $\begin{array}{l}\text { Low fear } \\
\text { High fear }\end{array}$ & $\begin{array}{c}10 / 81 \\
10 / 165\end{array}$ & $\begin{array}{c}0 / 06 \\
0 / 151\end{array}$ & $\begin{array}{l}0 / 20 \\
0 / 20\end{array}$ \\
\hline Injury avoidance & $\begin{array}{l}\text { Low fear } \\
\text { High fear }\end{array}$ & $\begin{array}{l}5 / 321 \\
3 / 067\end{array}$ & $\begin{array}{l}0 / 09 \\
0 / 12\end{array}$ & $\begin{array}{l}0 / 20 \\
0 / 20\end{array}$ \\
\hline Dependency reward & $\begin{array}{l}\text { Low fear } \\
\text { High fear }\end{array}$ & $\begin{array}{l}9 / 967 \\
9 / 022\end{array}$ & $\begin{array}{l}0 / 026 \\
0 / 268\end{array}$ & $\begin{array}{c}0 / 026 \\
0 / 00\end{array}$ \\
\hline
\end{tabular}

Table 4. Emotional characteristics subscale test results

\begin{tabular}{cccc}
\hline Variable & Test & Df & P \\
\hline Novelty seeking & $0 / 752$ & 87 & $0 / 454$ \\
Perseverance & $1 / 031$ & 87 & $0 / 305$ \\
Injury avoidance & $2 / 007$ & 87 & $0 / 048$ \\
Dependency reward & $2 / 573$ & 1 & $0 / 109$ \\
\hline
\end{tabular}

Table 5. T-test results of two independent communities

\begin{tabular}{cccc}
\hline Variable & T-Test & Df & P \\
\hline Emotional features & $2 / 426$ & 87 & $0 / 017$ \\
Reassessment strategy & $2 / 057$ & 87 & $0 / .48$ \\
Emotional Inhibition str & $0 / 666$ & 87 & $0 / 507$ \\
\hline
\end{tabular}




\section{Conclusion}

The aim of this study was to compare the emotional characteristics of personality and psychological problems and cognitive emotion regulation strategies and marital adjustment in women with high fear and low fear of marital infidelity.

The findings of the present study showed that the emotional characteristics of personality in women with high fear and low fear are significantly different. Emotional personality traits were assessed based on the Cloninger questionnaire. A study that had previously examined this relationship based on the Cloninger questionnaire was not found. But in general, there seems to be a relationship between the emotional characteristics of the character and the fear of marital infidelity. Most studies have examined this relationship based on personality constructs such as the five personality factors (neo) and the three Eisenhower personality factors. In these studies, it was shown that personality style plays an important role in predicting their marital relationships. An inhouse study comparing the personality traits and attachment styles of unfaithful women, unfaithful men, and normal wives. The results showed that betrayed women (court) had higher neuroticism and betrayed women (counseling centers) had higher conscience than normal women. There is a significant difference between the level of anxiety and avoidance of attachment in women in counseling centers and women in court (Torabiyan, 2011). Some researchers believe that among the predictors of marital infidelity, personality and individual factors, factors related to marital relationship and the degree of satisfaction with the relationship and macro social and cultural factors and environmental factors (Khedmatgozar, Bolhari \& Karamlou, 2008).

Considering that in the present study, the trauma characteristic in Butters women was less than infidelity, it can be argued that since the trauma indicates excessive anxiety, worry, cowardice, pessimism and skepticism, so despite having this Personality Traits There was a possibility of betrayal. This personality trait is also biologically related to the level of the neurotransmitter serotonin, which subconsciously commits risky behaviors, including adultery, to increase serotonin levels. In addition, this trait can overlap with other personality traits, such as nouveau riche, which is associated with the neurotransmitter dopamine, as this trait can also lead people to engage in risky behaviors, including infidelity. Therefore, it can be argued that people with high vulnerability can be more likely to commit adultery than other people.

According to the findings of the present study, there is no significant difference between women's cognitive function with high and low fear of marital infidelity. Although, given the few studies that have been similar to this one in the past, we guessed that there was a difference between the two groups in this feature, but this hypothesis was not confirmed. Previous research has shown the effect that chewing on infidelity can be so severe and uncontrollable that it disrupts a person's daily functioning and concentration, and changes a person's beliefs about and relationship with his or her spouse that make him or her no longer trust his or her spouse. To have and feel safe in relation to him, they say. However, in the present study, in which cognitive function was measured based on the Montreal Cognitive Questionnaire, which measures cognitive characteristics such as memory, intelligence, concentration, and attention, it can be explained that the two groups differed in these characteristics. They do not and their scores have been normal. Therefore, the anxiety and fear that these women experience was not enough to affect their memory, attention and concentration.

The findings of the present study on the difference between women with high fear and low fear of betrayal in cognitive strategies for regulating their emotions confirm this hypothesis. Although there was no difference in the characteristics of the emotion inhibition strategy between the two groups based on these findings, women who reported less fear had higher mean scores of reassessment strategies, indicating that these women were more proportionate in managing their emotions. To a group that experiences more fear, they perform better.

Also, according to the findings of the present study, there is a significant difference between women's marital adjustment with high fear and low fear of marital infidelity, and the average of this feature is 
higher in women with low fear. Although no previous study has examined this relationship, it has been found that the results of this study on the differences between women with high fears and low fears of marital infidelity in marital adjustment can be compared with studies that it has already been done in the same fields. Positive emotional cognitive regulation, with its effect on improving extroverted personality traits and reducing neuroticism in couples, helps to improve the quality of marital relationships and couples' satisfaction with cohabitation. (Zare \& Rezaei, 2016). Sexual pornography seems to have a negative effect on love and marital satisfaction (Jafarzadeh Fadaki, Amani, 2015).

One of the limitations of this study is the available sampling and the reluctance of some women due to the taboo of marital infidelity and the high number of variables studied. Since this research has been done quantitatively and the underlying factors may have been ignored, interested researchers are advised to conduct qualitative studies and in-depth study of the factors affecting women's fear of marital infidelity.

\section{Ethical Considerations}

Compliance with ethical guidelines: In this study, due to the lack of clinical intervention, the code of ethics was not used, but after initial interviews with participants and their informed verbal consent, they participated in this study. Dedicated to both groups.

Funding: This research has been done in the form of a master's thesis at the personal expense of the authors.

Authors' contribution: The first author was the main researcher in charge of this research and the second and third authors were equally involved in the research.

Conflict of interest: The authors do not express any conflict of interest in this study.

Acknowledgments: The participation of the participants in the research and the efforts of the supervisors and advisors are sincerely thanked and appreciated. 
مقايسه ويز حىهاى هيجانى شخصيت، عملكرد شناختى، راهبردهاى تنظيم شناختى هيجان و ساز كارى زناشويى در زنان

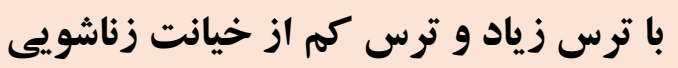

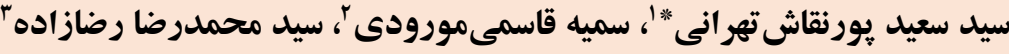

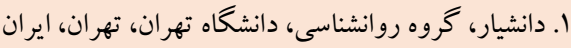

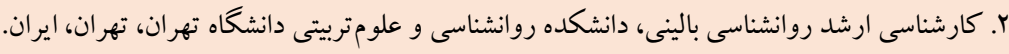

r. استاديار، دانشكده روانشناسى و علومتربيتى دانشكاه تهران، تهران، ايران.

جكيu

زمينه: علىرغم بيجيجيدى و شيوع بالاى خيانت زناشويى و بيامدهاى ناگوار و بار هيجانى در روابط زناشويى بويزه در زنان، به دليل تابو بودن، تحقيقات كمى در اين زمينه موجود است. هدف: يزوهش حاضر با هدف مقايسه ويزّ گیىهاى هيجانى شخصيت و عملكرد شناختى و راهبردهاى تنظيم شناختى هيجان و ساز گارى

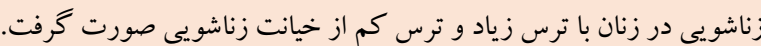
روش: بدين منظور طى يكك تحقيق على مقايسهاى 1 زن نه صورت نمونهُ در دسترس از بين زنان متأهلى كه بدليل مشكلات زناشويى به

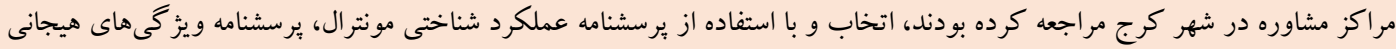

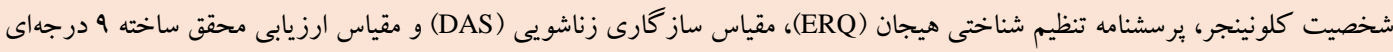
ترس از خيانت، مورد ارزيابى قرار گرفتند. دادهها از طريق نرمافزار SPSS-23 و روش تحليل عاملى و با استفاده از آزمون t مستقل و آزمون نايار امترى من - ويتنى تحليل شد.

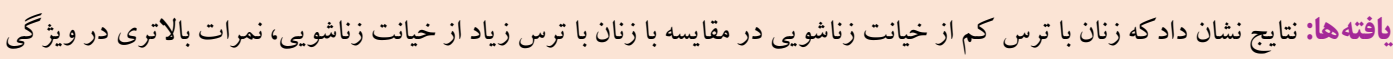

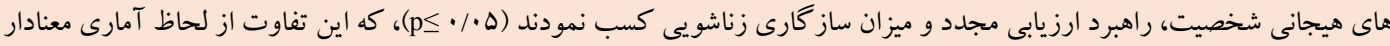

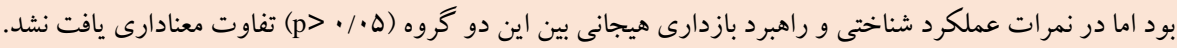

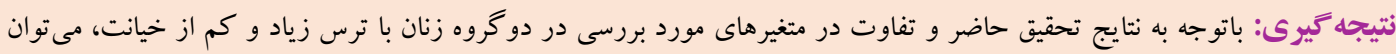

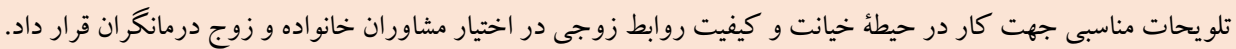

مشخصات مقاله

كليدوازمها: ويزز گیى هاى شخصيت، عملكرد شناختى، راهبردهاى شناختى تنظيم هيجان،

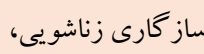
ترس از خيانت زناشويى

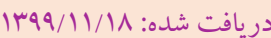

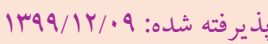

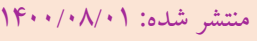

* نويسنده مسئول: سيد سعيد يورنقاشتهرانى، دانشيار، دانشكده روانشناسى و علومتربيتى دانشكاه تهران، تهران، ايران.

رايانه: Spnaghash@ut.ac.ir

تلفن: 
از باز گشت به شرايط دشوار گذشته)؛ و تم افزايش و ترويج فرهنك خيانت

dolto

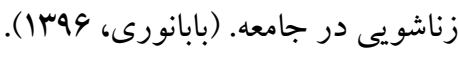

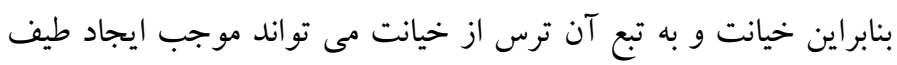

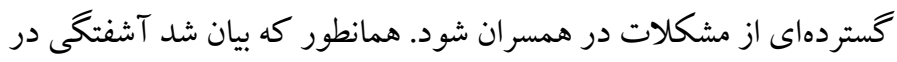
عملكرد شناختى يكى از ييامدهاست. اصطلاح شناخت به فر آيندهاى درونى ذهنى يا راههايى كه در آنها اطلاعات يردازش مىشوند، يعنى راه

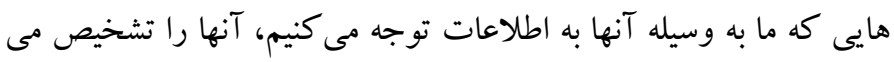
دهيم، به رمز درمى آوريم، در حافظه ذخيره مىسازيم و هر زمان كه نياز

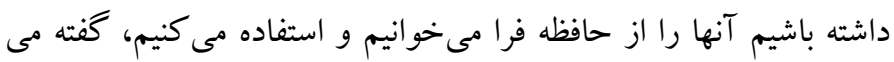

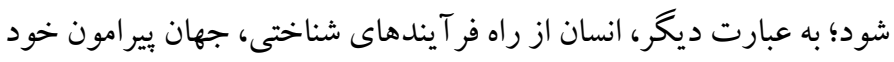

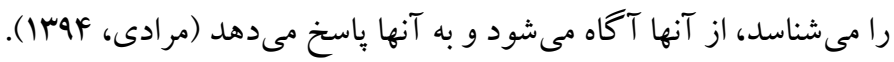

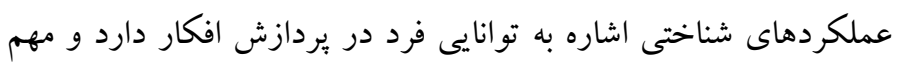
ترين حوزههاى شناختى در ارزيابىهاى عصب روانشناختى شامل هوش،

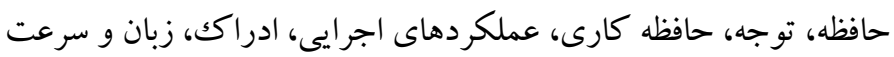

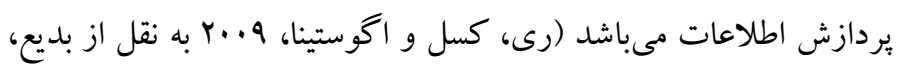

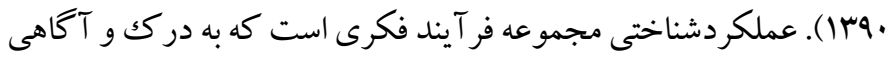

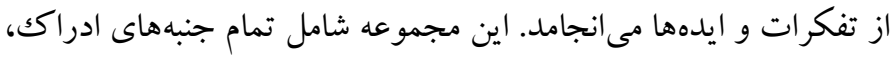

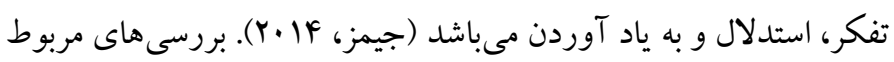

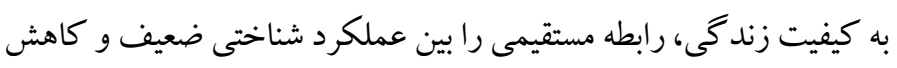

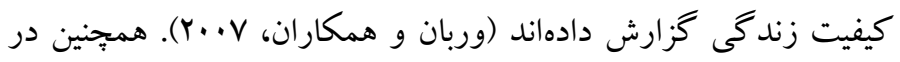

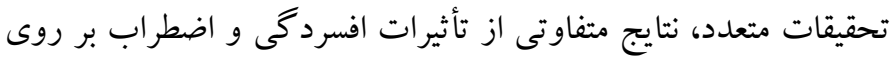

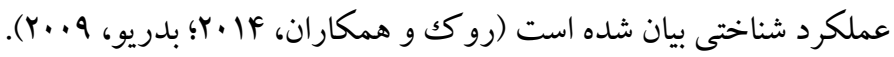

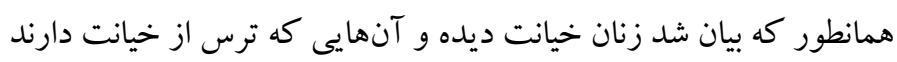
با اضطرابهاى زيادى مواجه مىشوند و اين مى تواند بر عملكرد شناختى آنان تأثير بخذارد. هيجان نقش مهمى در جنبههاى مختلف زندگى نظير ساز گارى با تغييرات

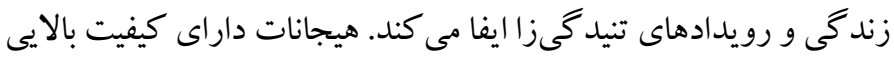
هستند به اين صورت كه مى توانند باعث واكنش مثبت يا منفى در افراد

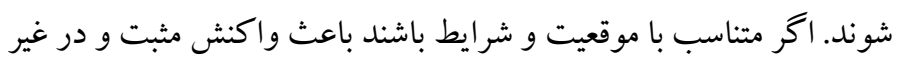
اين صورت باعث واكنش منفى مى شود. بنابراين زمانى كه هيجانات شديد

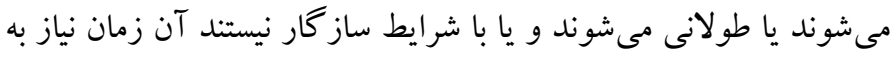

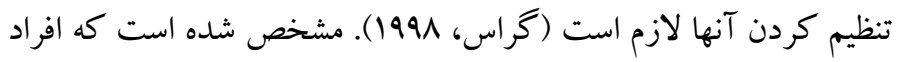

خانواده در زمره مهم ترين سيستمهاى اجتماعى است كه بر اساس ازدواج بين دو جنس مخالف شكل مى گيرد. حفظ و تداوم خانواده از اهميت

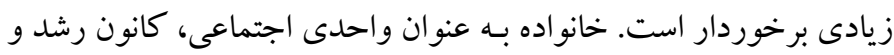

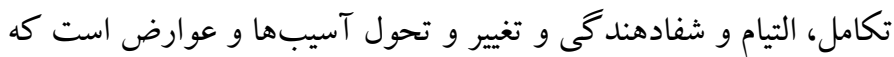

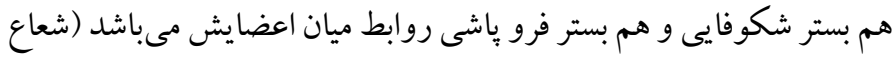

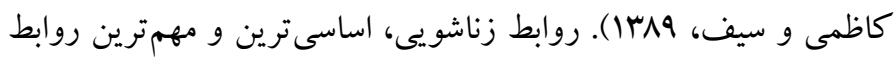

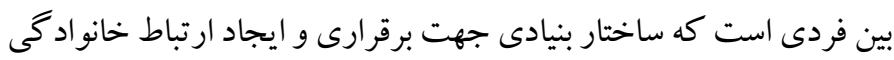

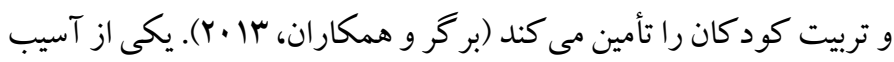

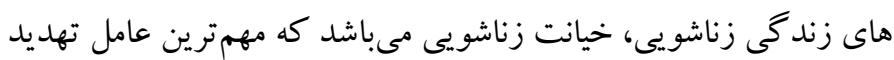

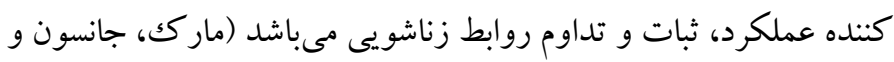

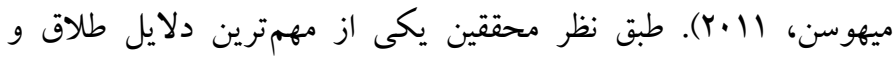

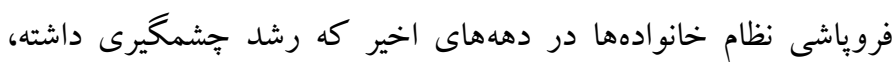
خيانتهاى زناشويى و روابط فرازناشويى مىباشد (يلوسو، سا •r).

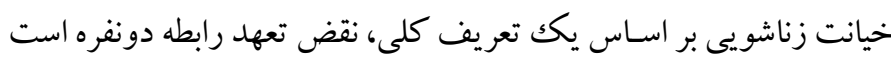

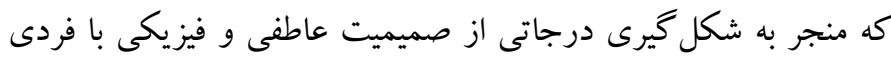

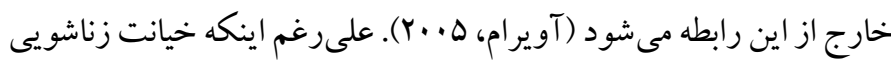

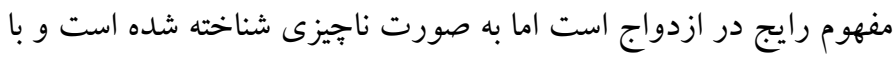
توجه به تابو بودن مسئله، ييشينه و بررسى روشنى در ارتباط با اين موضوع

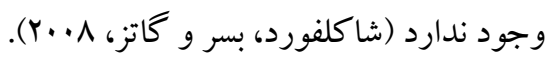

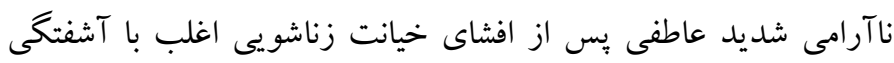

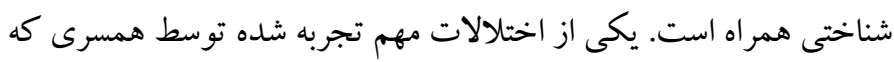

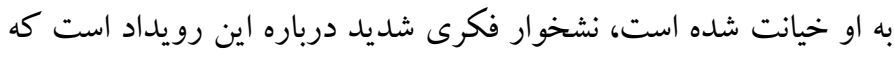

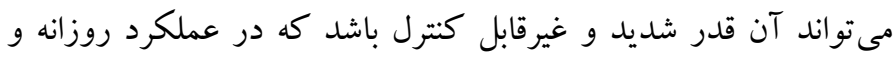

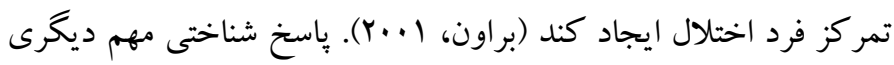

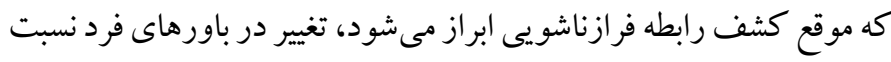

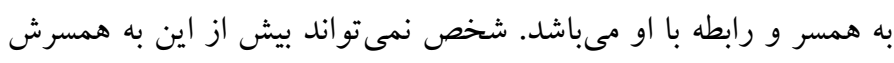

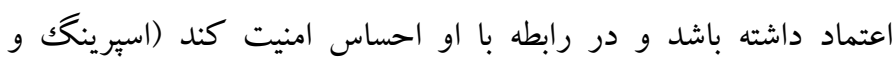

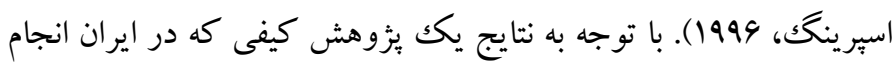
شده، مشخص شد كه دو عامل زيربنايى و اصلى در ظهور نشانهاى ترس

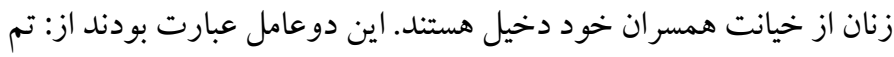

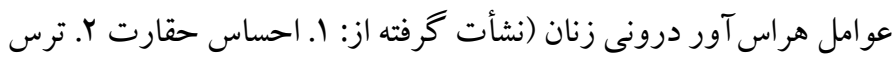


زندگى زناشويى با احساس رضامندى بيشترى همراه است. عوامل متعددى

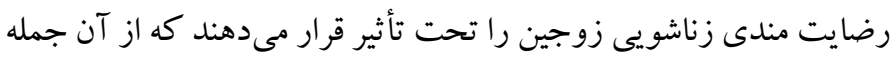

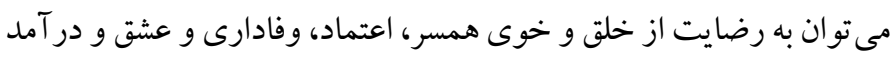

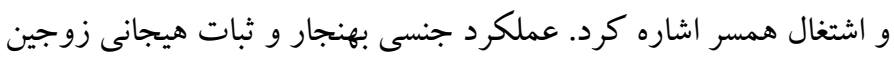

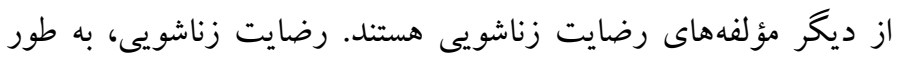

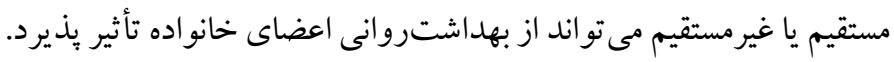
بهداشتروان، دانش و هنرى است كه به افراد كمكك مى كند تا با ايجاد روشهايى صحيح از لحاظ روانى و عاطفى بتوانند با محيط خود ساز كارى داشته و راهحل هاى مطلوبترى براى حل مشكلات انتخاب نمايند (به نقل

$$
\text { از جوانمرد، قره قوزلو و يوراكبران، ههسا ). }
$$

به نظر مىرسد هرزه نغارى جنسى بر عشق و رضايت زناشويى، تأثيرى

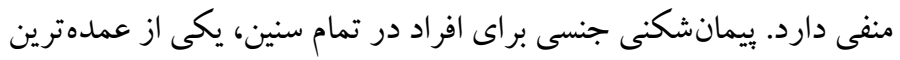

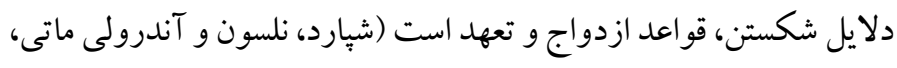

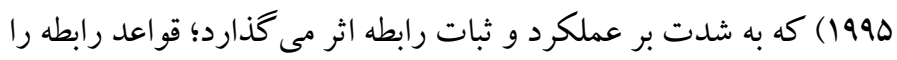
برهم مىزند و خلاف انتارات طرف مقابل است (دريخو تاس، سفستروم و جنتيليا، 1999؛ ويزمن، ديكسون و جانسون، (997). همجنين اعتمادى را كه رابطه براساس آن شكل گرفته است، مخدوش مىسازد (فلدمن و كافمن، 1999). اين ويمانشكنىها ممكن است به عنوان عامل آسان كننده

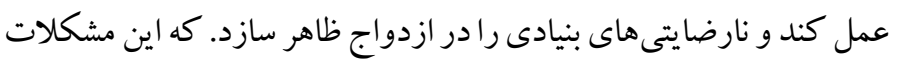

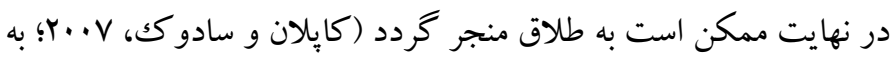

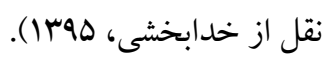

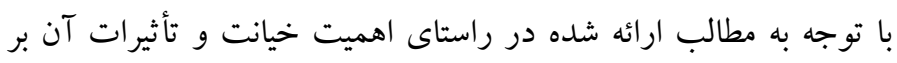
كيفيت زندگى زناشويى، و بزوهشهاى به كمى كه در ايران صورت كرفته در بزوهش حاضر قصد داريم به اين مسئله ببردازيم كه آيا بين ويز هيجانى شخصيت و عملكرد شناختى و راهبردهاى تنظيم شناختى هيجان وساز گارى زناشويى در زنانى كه ترس زياد نسبت به خيانت زناشويى دارند

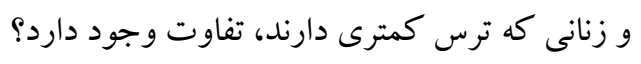

روش

الف) طرح هئوهش و شر كت كنند كان: يزوهش حاضر از لحاظ هدف از نوع تحقيقات كاربردى، از لحاظ روش از نوع تحقيقات على مقايسهاى مىباشد. جامعه يزوهش را كليه زنان متأهل شهر كرج كه به دليل مشكلات
در مواجهه با رويدادهاى استرسزا، از راهبردهاى تنظيم هيجان متفاوتى براى اصلاح يا تعديل تجربه ى هيجانى خود استفاده مى كنند (آلداو، نولن

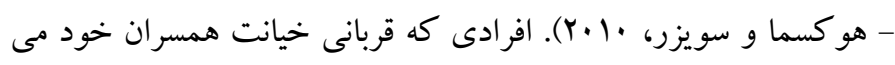

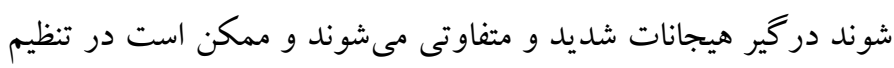

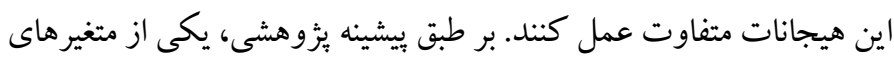

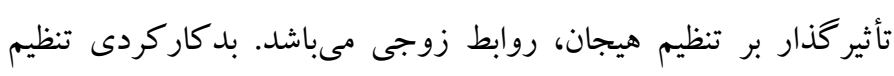
هيجانى و آشفتخى زناشويى در سطح فردى و زوجى با يكديخر رابطهاى

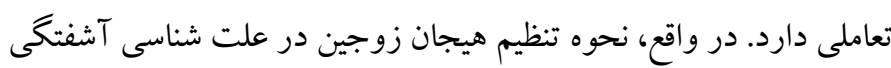

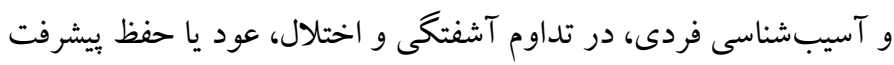

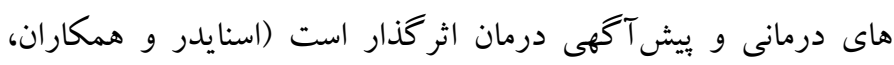

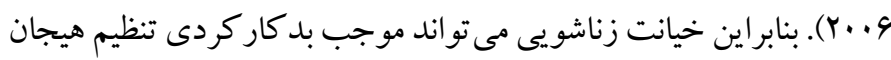

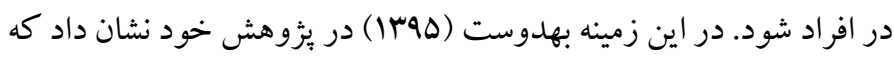

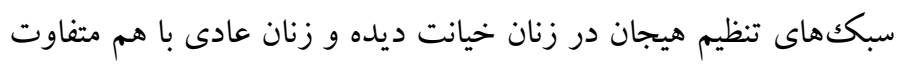
مىباشد. از طرفى سبك هاى تنظيم شناختى هيجان يكى از مؤلفهاى تأثير گذار بر

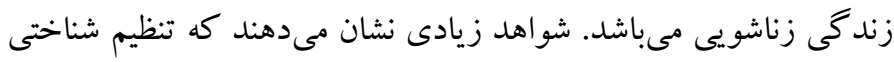

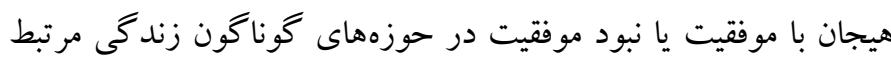

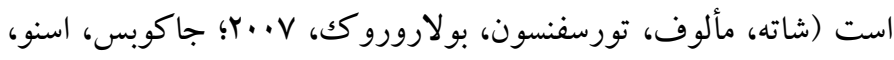

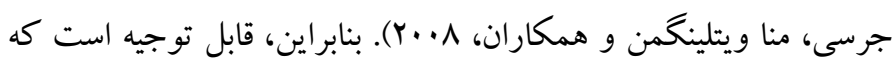

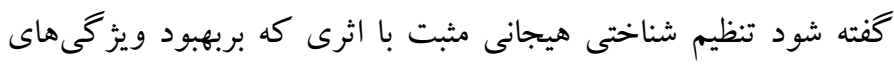

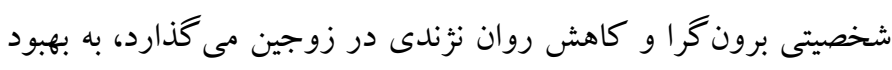

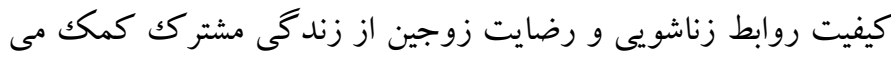

كند (زارع و رضايى، هوب1). براى توصيف سازكارى زناشويى از اصطلاحات متعددى مانند رضايت مندى، سازش، خشنودى، موفقيت و كيفيت زناشويى استفاده شده است.

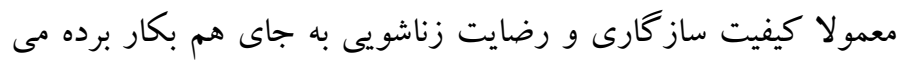

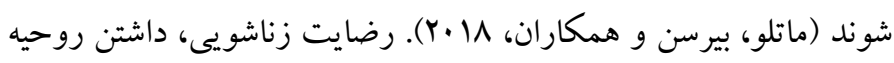

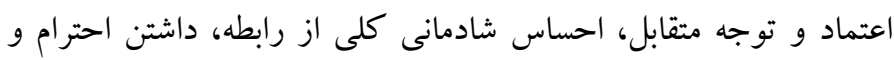
حمايت دوجانبه و داشتن ثبات در ازدواج تعريف شده است (جكسون،

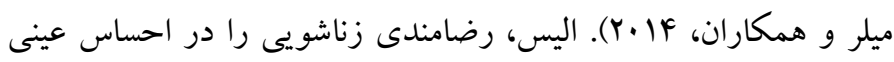
خشنودى، رضايت و لذت زن و شوهر از تمامى روابط خود تعريف مى

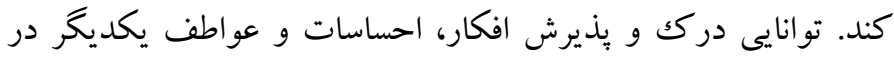


عدد بـا ب نمره و يادآورى ارقام به ترتيب و بر عكس، هر كدام (ا نمره)

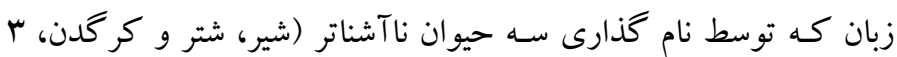

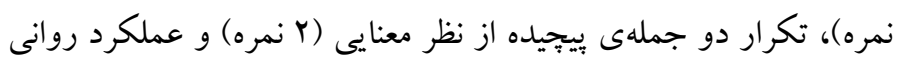

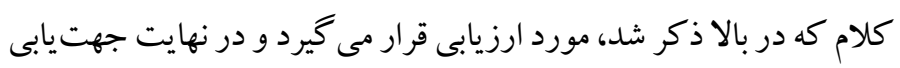
نسبت به زمان و مكان بررسى مىشود (4 نمره). براى تصحيح تأثير

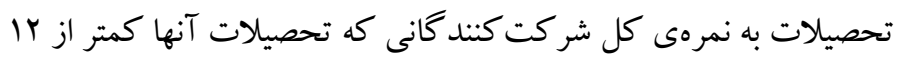
سال است، يكك نمره اضافه مىشود، البته در صورتى كـه نمره اى كه در

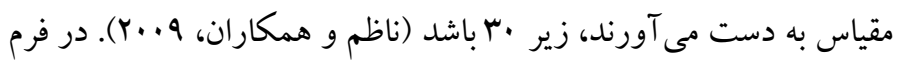

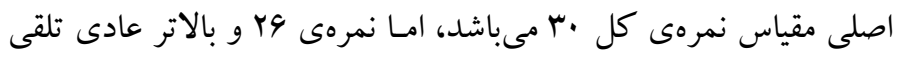

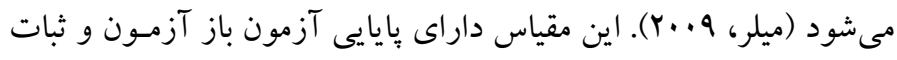
درونى خوبى است و نمرات آن با نمرات ساير مقياس هاى بـائ

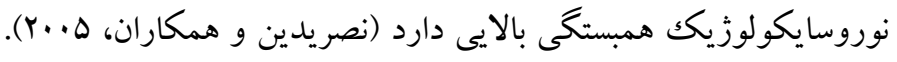

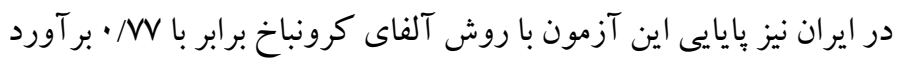

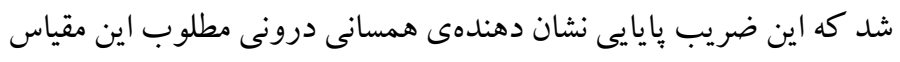
است همجنين براى بررسى حساسيت اين آزمون از روش تحليل تمايزات

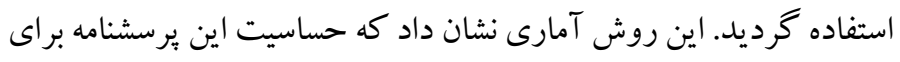

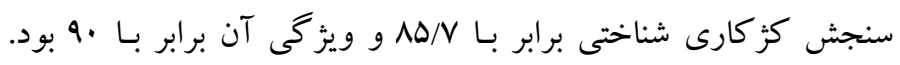

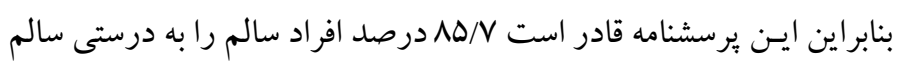
و •9 درصد افراد بيمار را به درستى بيمار تشـخيص دهد (به نقل از امساكى برسي

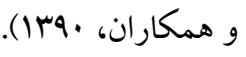
يرسشنامه ويزگ گىهاى هيجانى شخصيت: يرسشنامه سه بعدى شخصيت

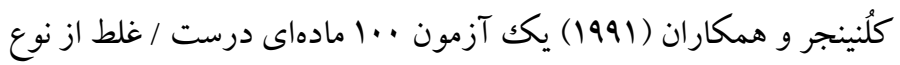
كاغذ - مدادى مىباشد كه سه بُعد شخصيت منجمله نوجويى، آسيب كريزى و ياداش وابسته را مورد سنجش قرار مى دهد (كُنينجر و همكاران،

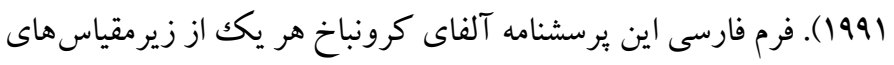

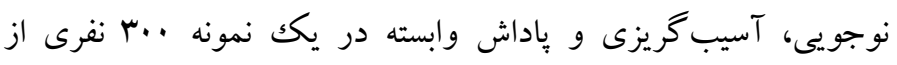

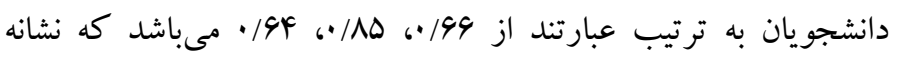
همسانى درونى قابل قبول برسشنامه مىباشد. يايايى آزمون - باز آزمون

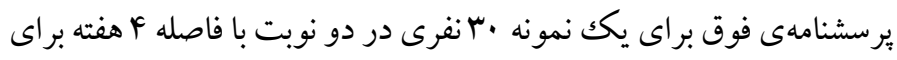

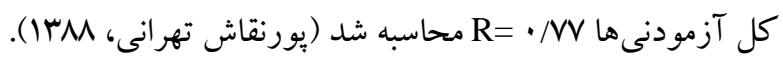

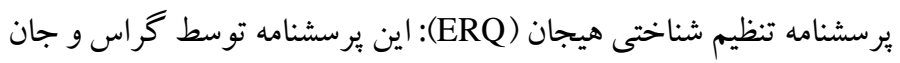

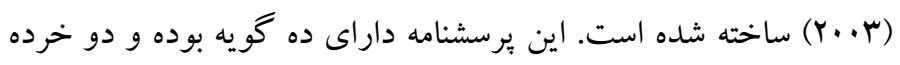

زناشويى در بهار و تابستان سال VQ به يكى از مراكز مشاوره راجعه كرده

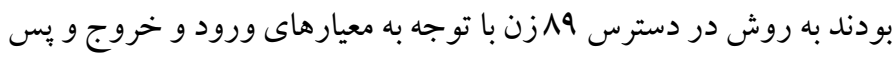

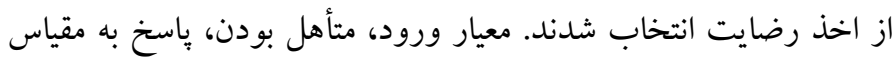
ارزيابى 9 درجه اى براى تعيين ميزان ترس از خيانت زناشويى، تمايل براى شر كت در ئزوهش و تكميل برسشنامهها. معيار خروج نيز شامل عدم تمايل

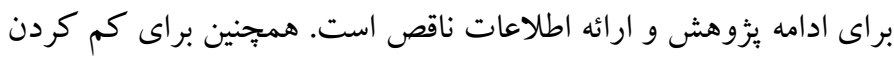

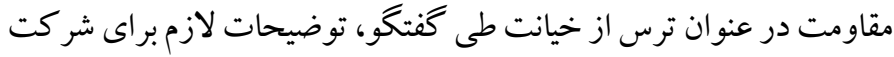

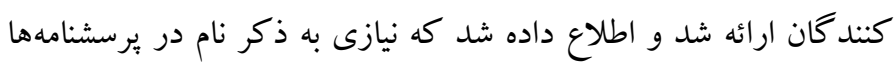

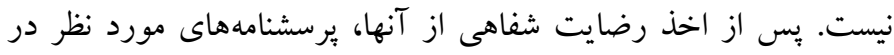

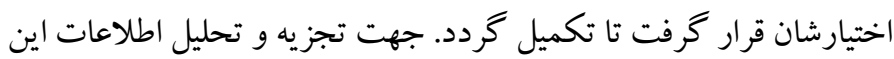
يزّوهش از روشهاى آمار توصيفى و استنباطى استفاده شده است. در بخش

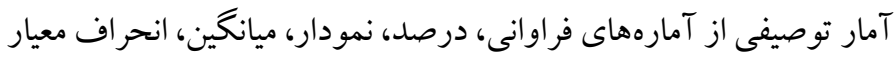

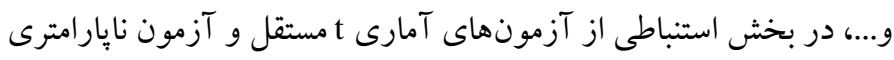

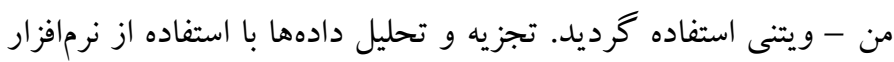
آمارى SPSS نسخه سץ انجام شده است.

ب) (بزار به منظور ارزيابى عملكرد شناختى از يرسشنامه ارزيابى شناختى مونترال (MoCA)

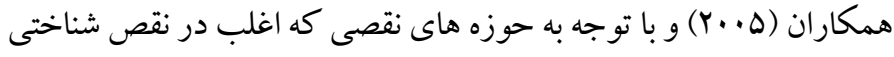
خفيـ (MCI) مشاهده مى شود، ساخته شد. نسـخهى اوليهى اين مقياس شامل • ا حوزمى شناختى بود كه با استفاده از تكاليف شناختى سريع و حساس، با اجر ايى راحت سنجيده مىشد. بِ از ينج سال استفادهى بالينى

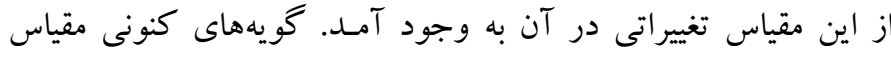

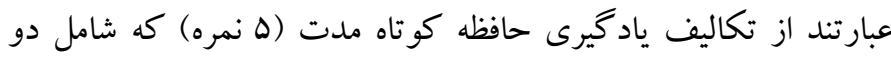
كوشش در يادگيرى ها نام و يادآورى آن پس از حدود هـ دقيقه است،

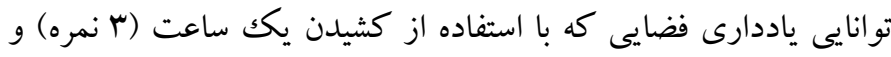

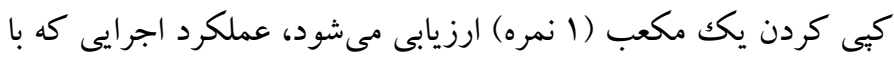

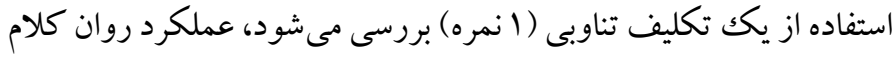
(ا نمره) و تكليف انتزاع كلامى دو گويه يا (Y نمره) سنجيده مى شودد، توجه، تمر كز و حافظهى فعال كه هر سه در تكليف توجه سنجيده مى شوده،

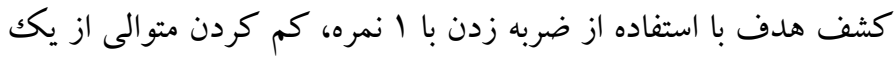


مقياس بازدارى هيجانى و ارزيابى مجدد پاسخها به هر آيتم در مقياس

بررسى اطلاعات جمعيت شناختى نشان داد تمامى افر اد يُوهش زن هستند

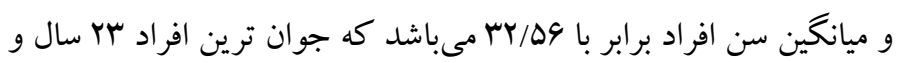

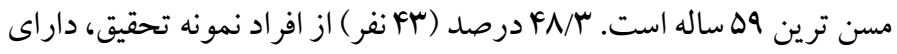

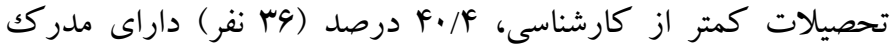

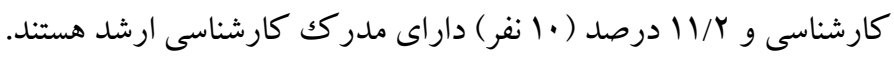

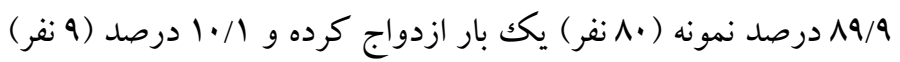

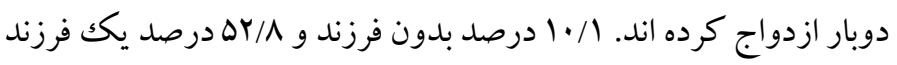
و و Y/Y درصد دو فرزند، 9/V درصد سه فرزند و //1/ درصد داراى جهار فرزند از ازدواج اولشان هستند. از $ه$ نفرى كه ازدواج دوم داشتند 1 نفر

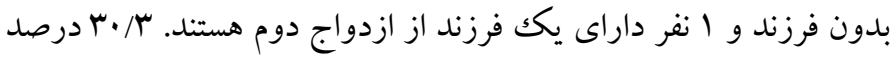
(نفر ) داراى شغل آزاد، وب درصد (·rV)

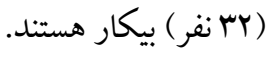

به منظور محاسبه نمرهُ برسشنامه هاى عملكرد شناختى، ويز گیىهاى هيجانى، راهبرد ارزيابى مجدد، راهبرد بازدارى هيجانى و ساز گارى زناشويى افراد

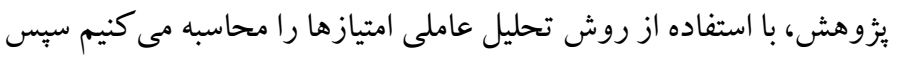

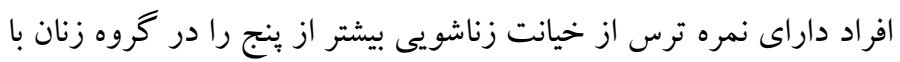

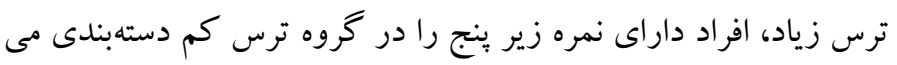

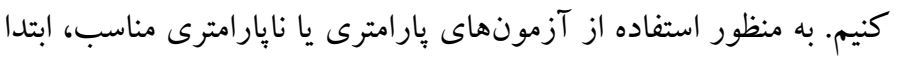

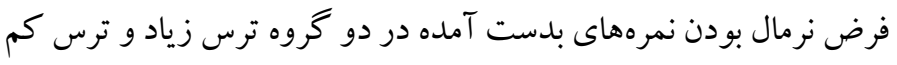

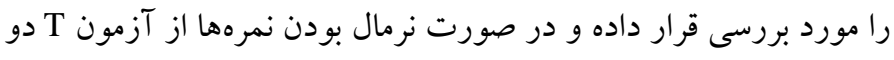

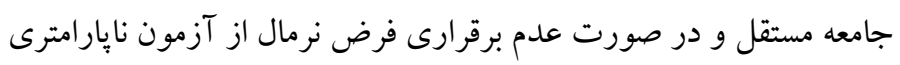
من - ويتنى استفاده مى كنيم. با توجه به اينكه فرض نرمال بودن برقرار نمىباشد (براساس جدول ())، بنابراين به منظور بررسى فرض بئوهش مبنى بر وجود تفاوت ميان ميزان

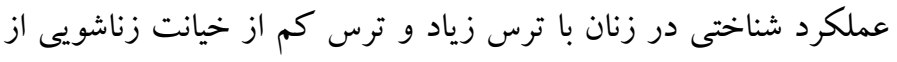

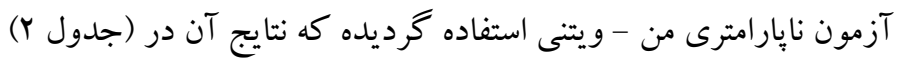

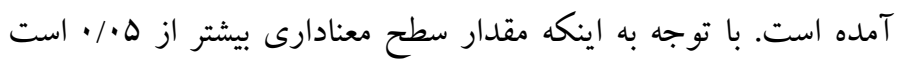
(p> بنابراين فرض صفر بذيرفته مى شود بدين معنا كه ميان ميزان

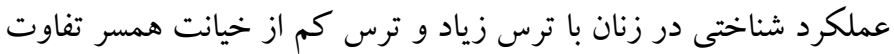

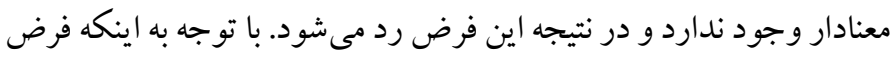

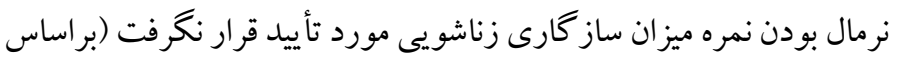

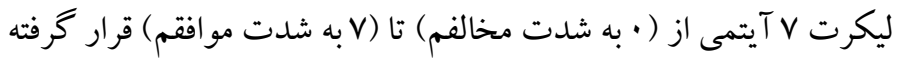

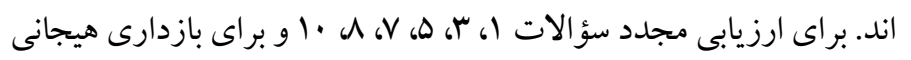

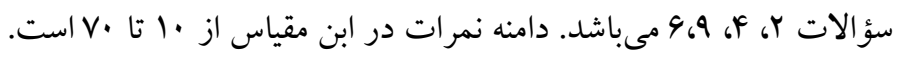

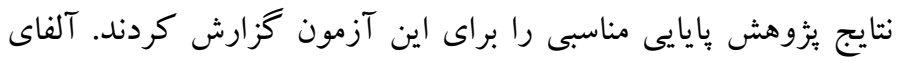

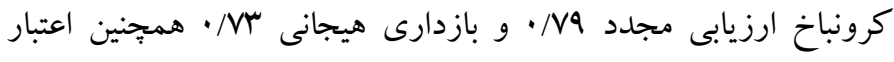
آزمون - آزمون مجدد در طول سه ماه براى هر دو مؤلفه اين برسشنامه

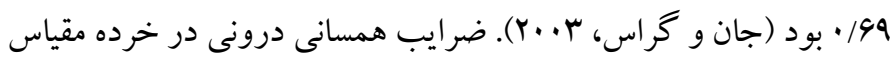

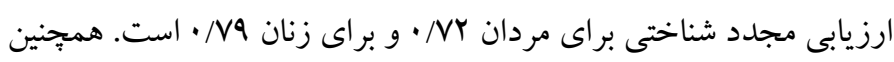
ضرايب همسانى درونى در خرده مقياسها بازدارى هيجانى براى مردان

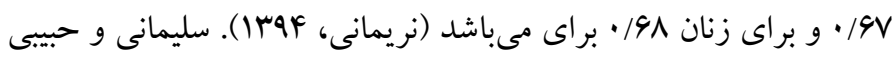

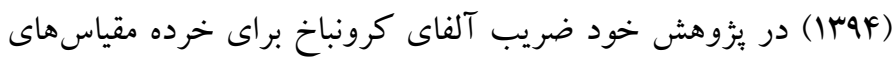

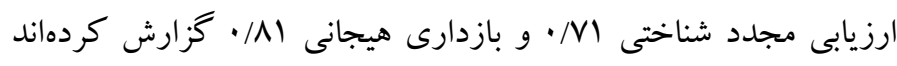

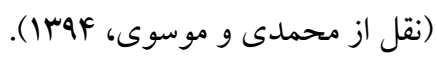

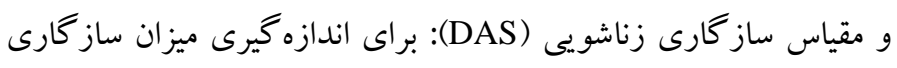

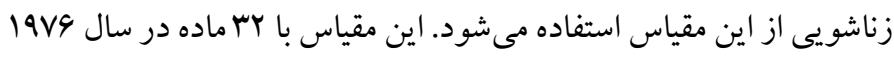

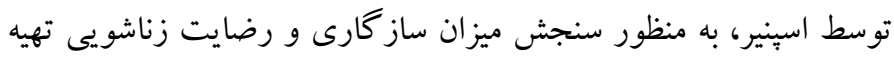

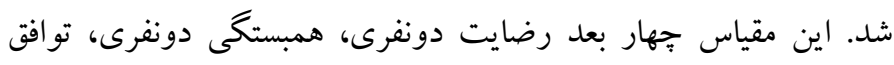
دونفرى و ابراز محبت را مىسنجد. در اين مقياس نمره كل مجموع تمام

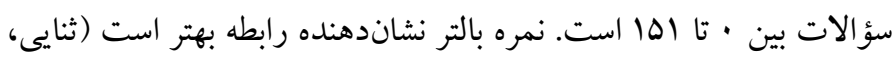
د IrAV

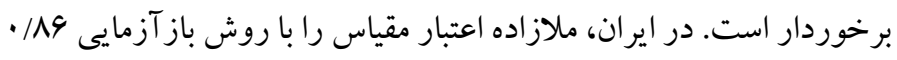

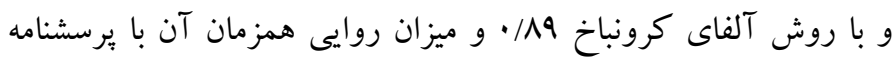

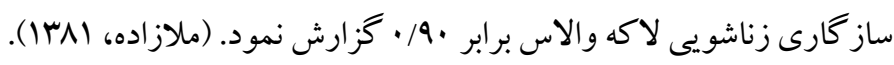
و مقياس ارزيابى محقق ساخته 9 درجهاى ترس از خيانت زناشويى: به

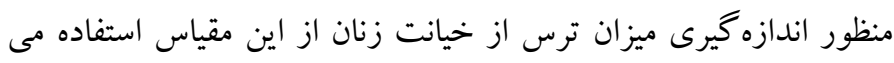

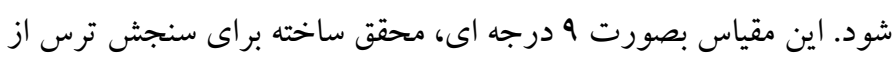

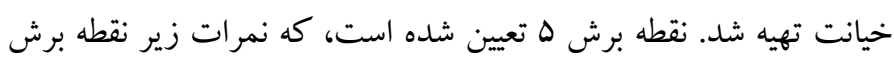

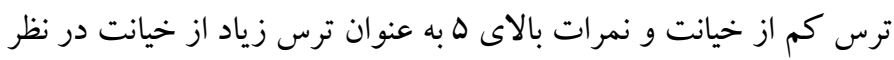
كرفته شده است. 
بنابر اين فرض صفر فقط در اين ويزگى رد مى شود بدين معنا كه ميان ميزان

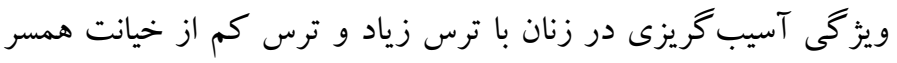

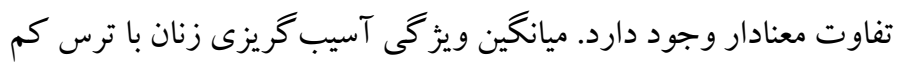

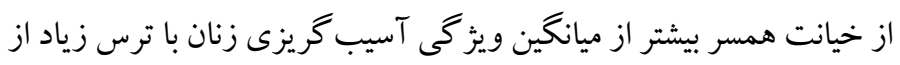

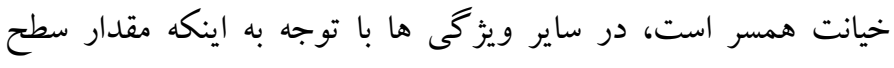

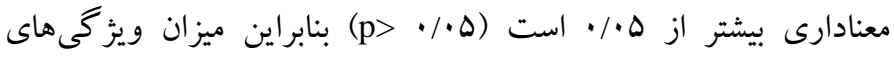
نوجويى، يشتكار و باداش وابستكى در زنان با ترس زياد و ترس كم از خيانت همسر يكسان است.

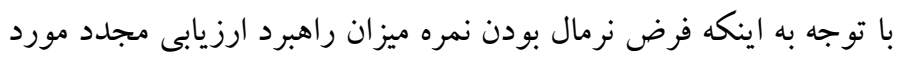

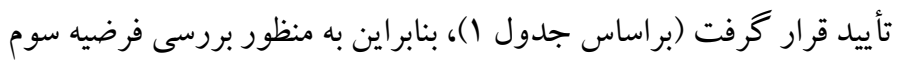
يُزوهش مبنى بر وجود تفاوت ميان ميزان راهبرد ارزيابى مجدد در زنان با

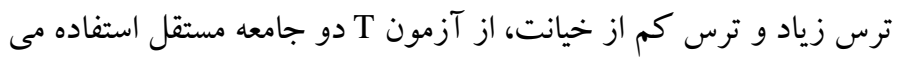
كنيم. براساس نتايج جدول ها، با توجه به اينكه مقدار سطح معنادارى كمتر

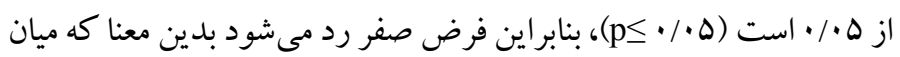

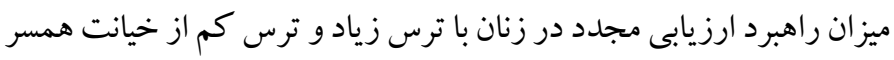

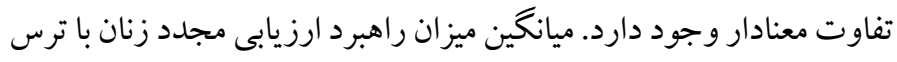
كم از خيانت همسر بيشتر از ميانخين ميزان راهبرد ارزيابى مجدد زنان با بان ترس زياد از خيانت همسر است، در نتيجه فرض تأييد مىشود. با توجه به ميه اينكه فرض نرمال بودن نمره ميز ان راهبرد بازدارى هيجانى مورد تأييد قرار

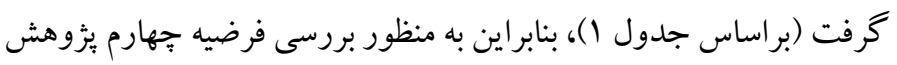

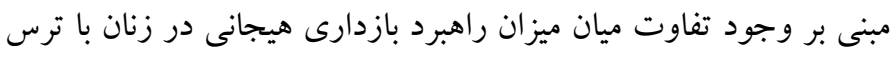
زياد و ترس كم از خيانت، از آزمون T دو جامعه مستقل استفاده مى كنيم. براساس نتايج جدول ه، با توجه به اينكه مقدار سطح معنادارى بيشتر از

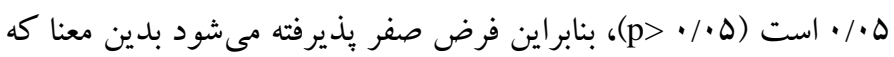
ميان ميزان راهبرد بازدارى هيجانى در زنان با ترس زياد و ترس كم از

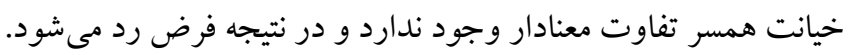

جدول ()، بنابراين به منظور بررسى فرض يُزوهش مبنى بر وجود تفاوت ميان ميزان ساز كارى زناشويى در زنان با ترس زياد و ترس كم از خيانت

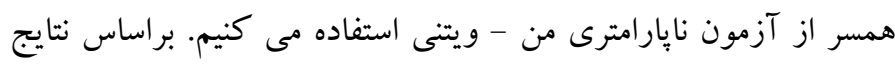

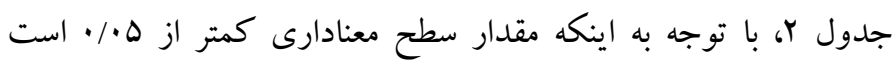

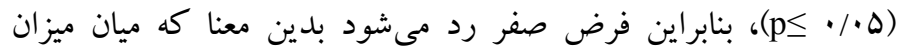

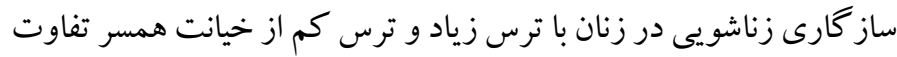

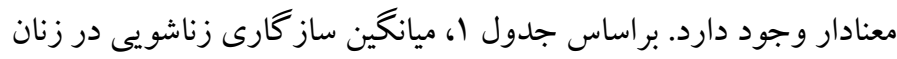
با ترس كم بيشتر از ساز گارى زناشويى در زنان با ترس زياد است. در نتيجه

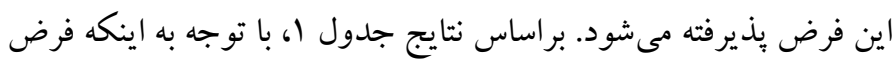

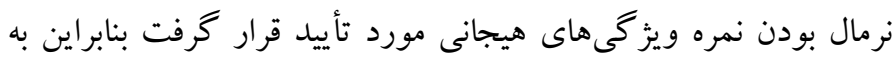

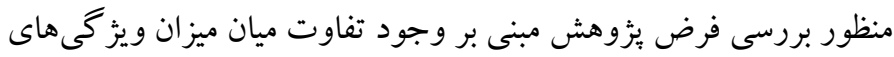

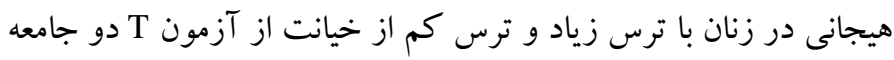
مستقل استفاده مى كنيم. با توجه به اينكه مقدار سطح معنادارى كمتر از

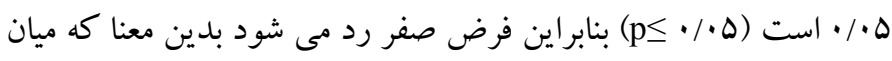

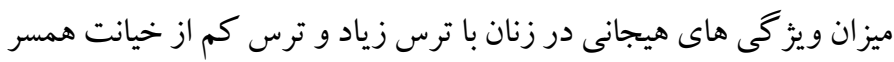

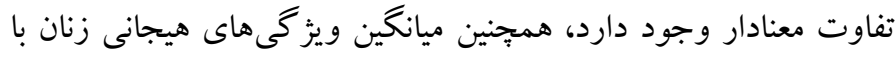

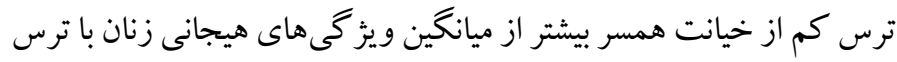
زياد از خيانت همسر است، در نتيجه اين فرض تأييد مىشود. براساس

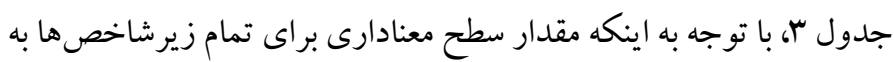

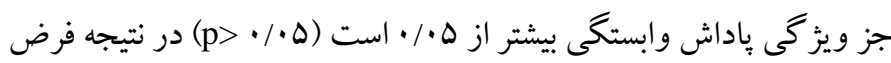

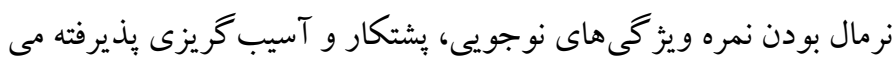

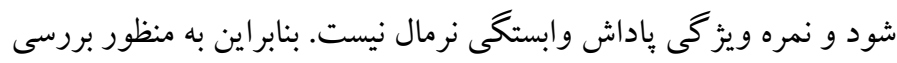

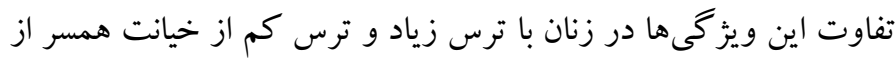

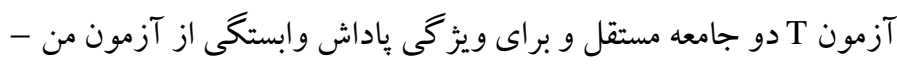

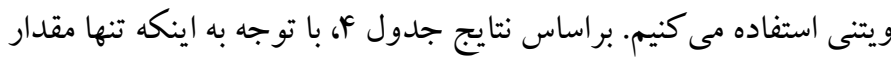

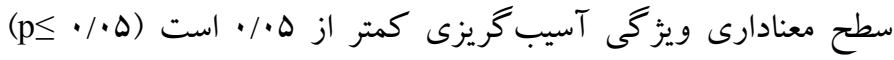

جدول ا. نتايج آزمون نرمال بودن و ميانغين متغير ها

\begin{tabular}{|c|c|c|c|c|c|}
\hline ميانگين & نتيجه & سطح معنادارى (p) & آماره كلمو گروف & ترس از خيانت & متغير \\
\hline rV/FFY & نرمال برقرار نيست & $\cdot / \cdot$ &.$/ 4 \cdot 9$ & ترس كم & \multirow{2}{*}{ عملكرد شناختى } \\
\hline YV/FVG & نرمال برقرار نيست & $\% 99$ & $\cdot / r r$ & ترس زياد & \\
\hline r & نرمال برقرار است & $\cdot / r$. & .1 .94 & ترس كم & \multirow{2}{*}{ ويزگ گى هاى هيجانى شخصيت } \\
\hline $\mathrm{rN} / \mathrm{VG}$ & نرمال برقرار است & $\cdot / r$ & 每 & ترس زياد & \\
\hline $19 / 11$ & نرمال برقرار است & $\cdot / r$. & .194 & ترس كم & راهبرد ارزيابى مجدد \\
\hline
\end{tabular}




\begin{tabular}{|c|c|c|c|c|c|}
\hline ميانگين & نتيجه & سطح معنادارى (p) & آماره كلمو گروف & ترس از خيانت & متغير \\
\hline $19 / 19$ & نرمال برقرار است & $\cdot / r$ &.$/ 149$ & ترس زياد & \multirow{3}{*}{ ميزان راهبرد بازدارى هيجانى } \\
\hline N/A9V & 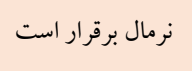 & $\cdot / r$ & .1 .91 & 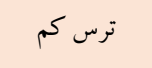 & \\
\hline N/TFF & نرمال برقرار است & $\cdot / \cdot \Delta F$ & $\cdot / \backslash A \vee$ & ترس زياد & \\
\hline$V D / F I V$ & ن رمال برقرار نيست & $\%$ &.$/ 191$ & 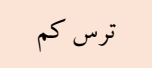 & \multirow{2}{*}{ ميزان ساز كارى زناشويى } \\
\hline Fq/Drq & نرمال برقرار نيست &.$/ 19$ & $\cdot / r \cdot V$ & ترس زياد & \\
\hline
\end{tabular}

جدول r. نتايج آزمون من - ويتنى

\begin{tabular}{|c|c|c|}
\hline ساز كارى زناشويى & عملكرد شناختى & آزمون \\
\hline$r \cdot 1$ & $99 \mathrm{~V} / 0 \ldots$ & آماره من - ويتنى \\
\hline$-r / 9 \Delta V$ &.$- / 190$ & $\mathrm{Z}$ \\
\hline$\%$ & $\cdot / 1999$ & سطح معنادارى (p) \\
\hline
\end{tabular}

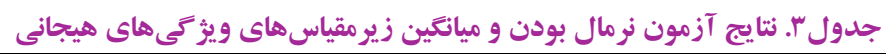

\begin{tabular}{|c|c|c|c|c|c|}
\hline ميانگين & نتيجه & سطح معنى دارى (p) & آماره كلمو گروف & ترس از خيانت & متغير \\
\hline $1 \% / 994$ & نرمال برقرار است & $\cdot / r$. & $\cdot / \cdot \mathrm{VA}$ & ترس كم & \multirow{2}{*}{ نوجويى } \\
\hline IT/YAY & نرمال برقرار است & $\cdot / r$. & ( & ترس زياد & \\
\hline $1 \cdot / 11$ & نرمال برقرار است & $\cdot / r$. & .1 .4 & ترس كم & \multirow{2}{*}{ يشتكار } \\
\hline $1 . / 190$ & نرمال برقرار است & $\cdot / r$. &.$/ 101$ & ترس زياد & \\
\hline$\Delta / r Y I$ & نرمال برقرار است & $\cdot / r$. & .1 .9 & ترس كم & \multirow{2}{*}{ آسيب گريزى } \\
\hline$r / .9 \mathrm{~V}$ & نرمال برقرار است & $\cdot / r$. &.$/ T r$ & ترس زياد & \\
\hline १/৭९V & نرمال برقرار نيست &.$/ r q$ &.$/$ rq & ترس كم & \multirow{2}{*}{ باداش وابستىى } \\
\hline$Q / \cdot r r$ & نرمال برقرار نيست & $\cdot / \cdot$ &.$/ 491$ & ترس زياد & \\
\hline
\end{tabular}

جدول ع. نتايج آزمون زير مقياس هاى ويزگ تهى هاى هيجانى

\begin{tabular}{|c|c|c|c|}
\hline سطح معنادارى (p) & درجه آزادى & آماره آزمون & ويز گى \\
\hline$\cdot / F \Delta F$ & $\Lambda V$ & - NOr & نوجويى \\
\hline$\cdot / r \cdot \Delta$ & $\wedge \vee$ & $1 / \cdot r 1$ & بشتكار \\
\hline 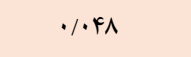 & $\Lambda \vee$ & $r / \cdots V$ & آسيبگ گريزى \\
\hline.$/ 1.9$ & 1 & $r / \Delta V T$ & ياداش وابستكى \\
\hline
\end{tabular}

جدول ه. نتايج آزمون T دو جامعه مستقل

\begin{tabular}{|c|c|c|c|}
\hline راهبرد بازدارى هيجانى & راهبرد ارزيابى مجدد & ويزگ گَىهاى هيجانى & \\
\hline .1994 & $r / \cdot \Delta V$ & T/FYG & T Tاره T \\
\hline$\wedge \vee$ & $\wedge \vee$ & $\wedge \mathrm{V}$ & درجه آزادى \\
\hline$\cdot / \Delta \cdot V$ &.$/ 4 \Lambda$ &.$/ .1 \mathrm{~V}$ & سطح معنادارى (p) \\
\hline
\end{tabular}

يافتهاى بثزوهش حاضر نشان داد كه ويز گى هاى هيجانى شخصيت در زنان با ترس زياد و ترس كم تفاوت معنادارى دارد كه از بين اين ويز گیىها،

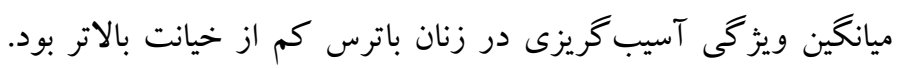

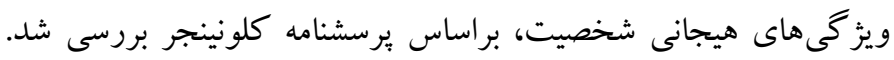

بحث و نتيجه تيرى يزؤهش حاضر با هدف مقايسه ويز گیىهاى هيجانى شخصيت و مشكلات

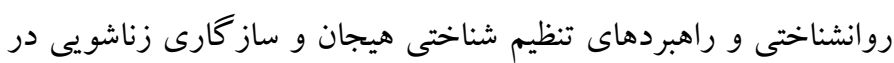
زنان با ترس زياد و ترس كم از خيانت زناشويى، انجام شد. 
طبق يافته هاى بزوهش حاضر، بين عملكرد شناختى زنان با ترس زياد و كم

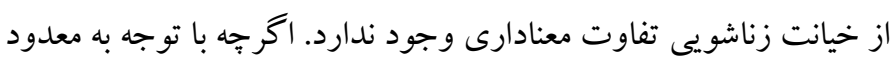
تحقيقاتى كه مشابه اين بثزوهش در كذشته انجام شده است، حدس ماند ما براين

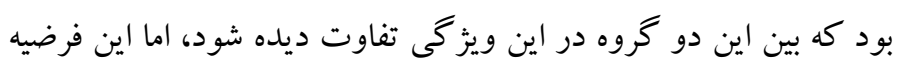

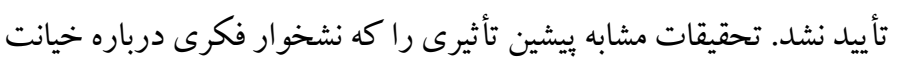

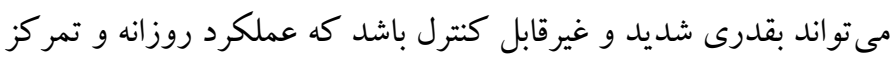

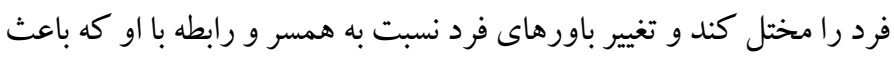

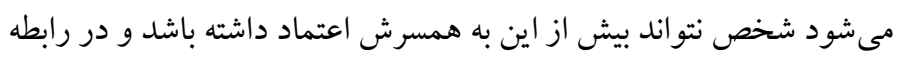
با او احساس امنيت كند، عنوان مى كنند. اما در تحقيق حاضر كه عملكرد شناختى براساس برسشنامه شناختى مونترال سنجيده شده است، و اين

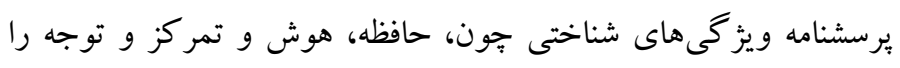

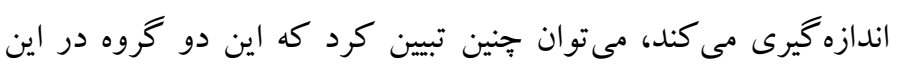

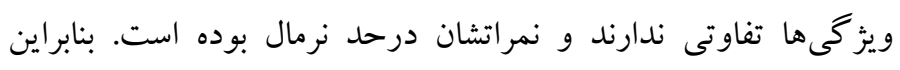
اضطراب و ترسى كه اين زنان تجربه مى كنند به حدى نبوده كه روى حافظه

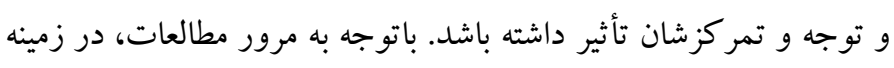

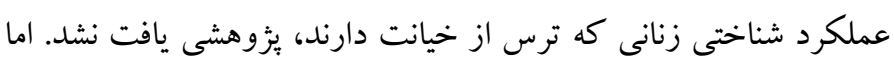

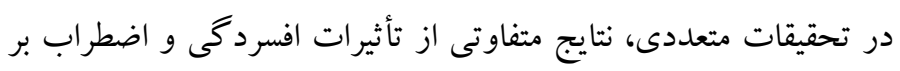

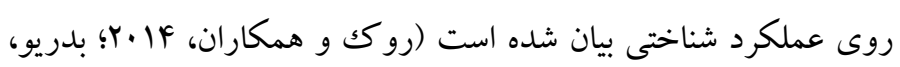

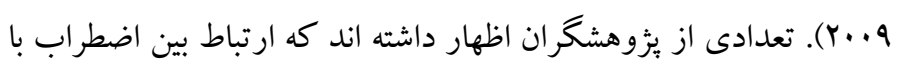
عملكرد شناختى به شكل يكك منحنى است. آنها بر اين باور هستند كه آنه

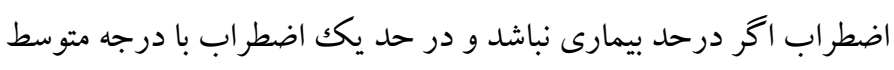

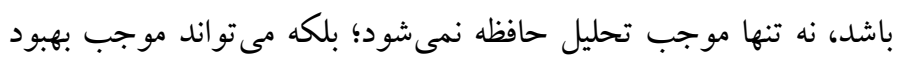

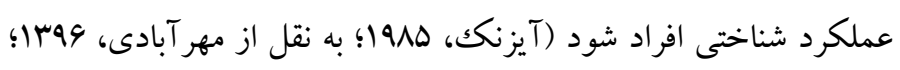

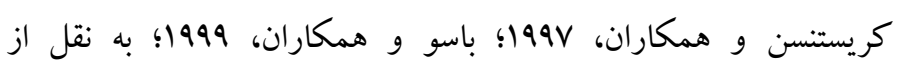

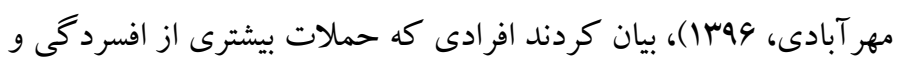

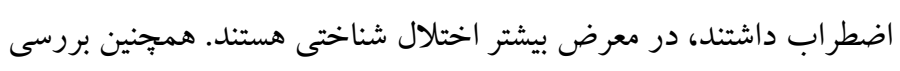

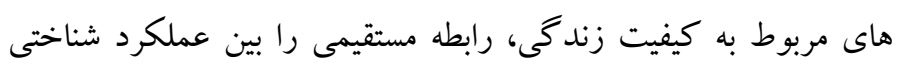
ضعيف و كاهش كيفيت زندگى گزارش دادهاند (وربان و همكاران،

(Y..V

يافتهاى بثزوهش حاضر مبنى بر تفاوت بين زنان با ترس زياد و ترس كم

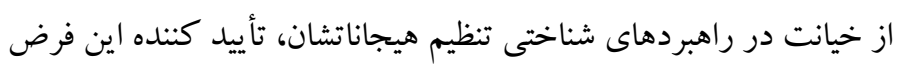

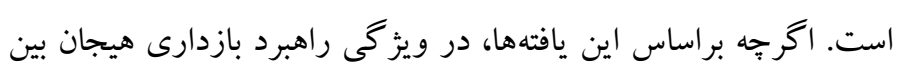

مطالعهاى كه بيش از اين به بررسى اين رابطه براساس برسشنامه كلونينجر

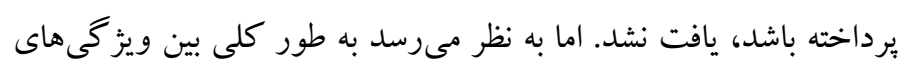

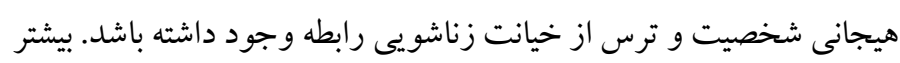

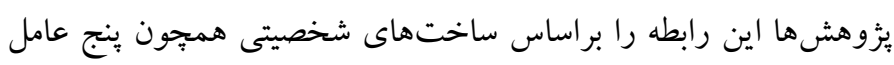

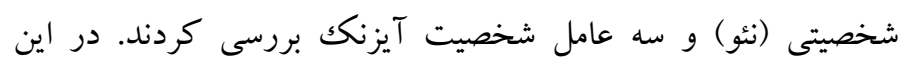

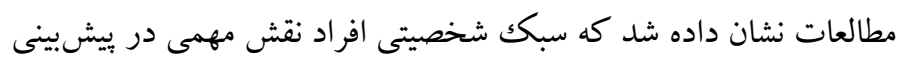
روابط زناشويى آنان دارد. يثزوهشى كه در داخل كشور در اين زمينه انجام

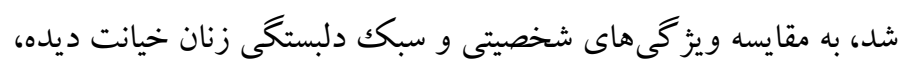

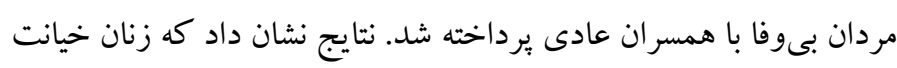
ديده (داد گاه) ميزان نوروتيكك بالاتر و زنان خيانت ديده (مراكز مشاوره)

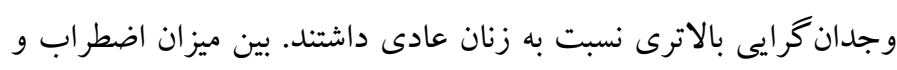

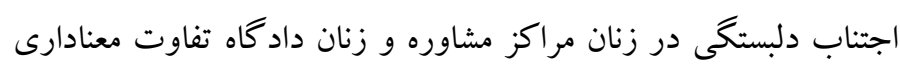

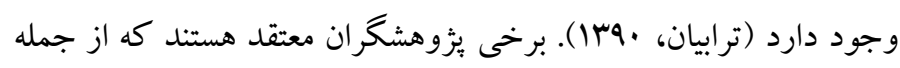
بيشبينى كنندهاى خيانت زناشويى، عوامل شخصيتى و فردى، عوامل مربوط به رابطه زناشويى و ميزان رضايتمندى از رابطه و عوامل كلان

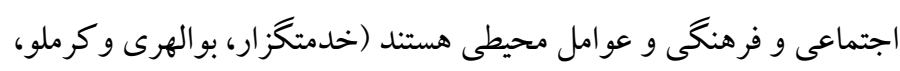

.(IHAV

با توجه به اينكه در مطالعه كنونى ويزگ گى آسيبگ كريزى در زنان باترس كم

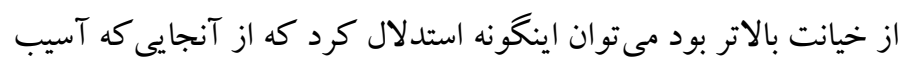

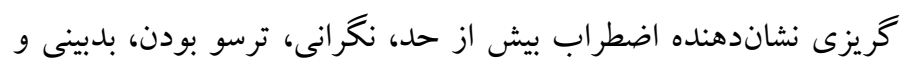

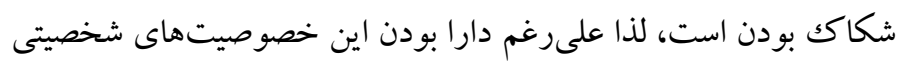

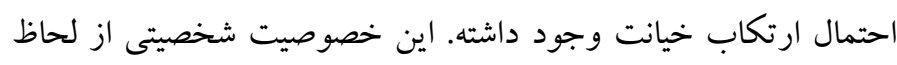

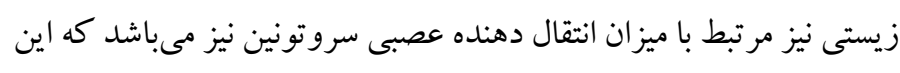

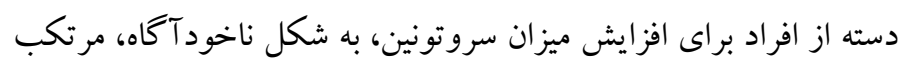

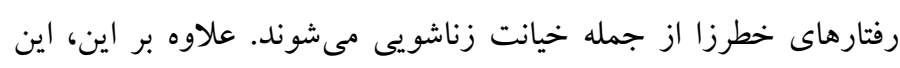
خصوصيت مى تو اند با خصوصيت ديخر شخصيتى از جمله نوجويى، كه با ريا

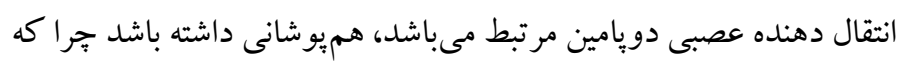

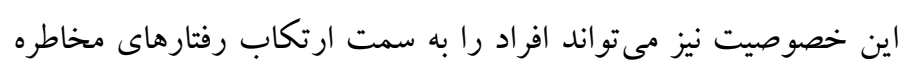

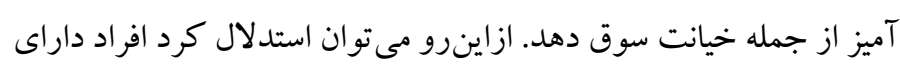

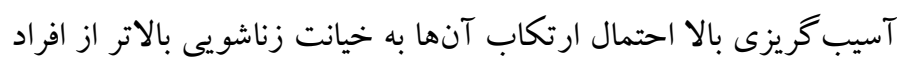
ديخر مىتواند باشد. 
قبلا در زمينهاى مشابه انجام شده همسو و هماهنك دانست. تنظيم شناختى

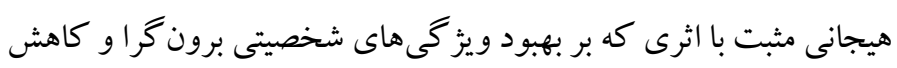

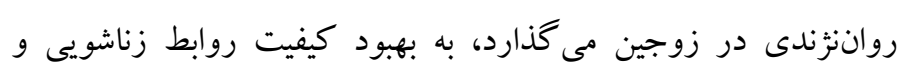

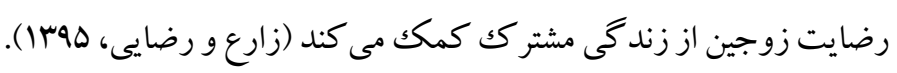

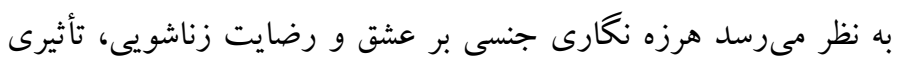

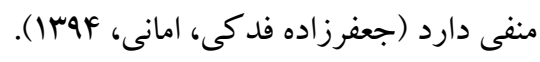

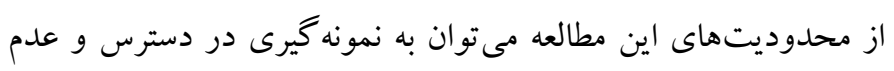

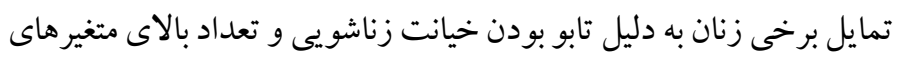

$$
\text { مورد بررسى اشاره كرد. }
$$

از آنجا كه اين بثزوهش بصورت كمئ انشى انجام شده و ممكن است عوامل

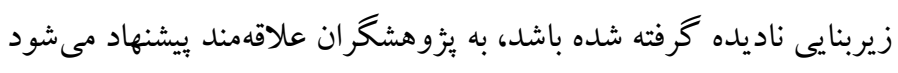
در اين زمينه مطالعات كيفى و بررسى عميق عوامل مؤثر بر ترس زنان زئن از

$$
\text { خيانت زناشويى مورد يززوهش قرار خيرد. }
$$

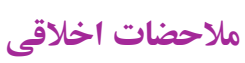

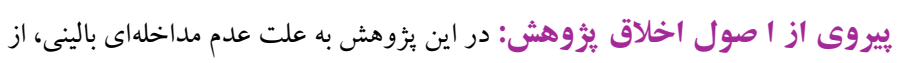

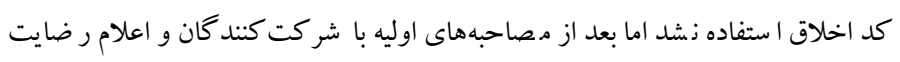

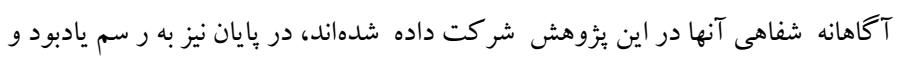

$$
\text { سياس زارى هديهاى، به هر دو گروه تقديم شد. }
$$

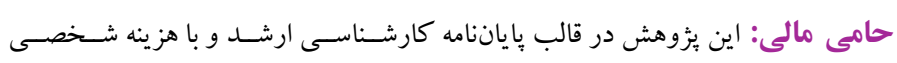
نويسند كان انجام شده است.

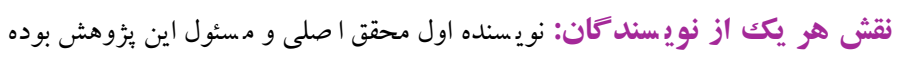

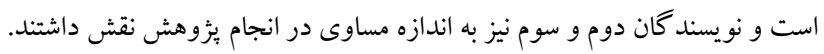

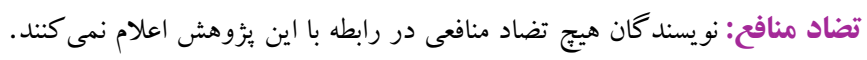

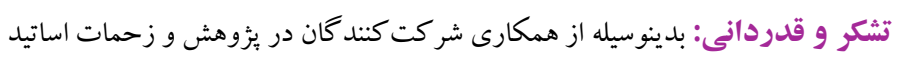
راهنما و مشاور صميمانه تشكر و قدردانى مى قرد دد.
اين دو گروه تفاوتى ديده نشد، اما زنانى كه ترس كمترى را گزارش دادند،

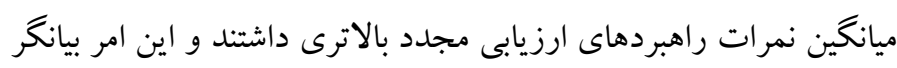

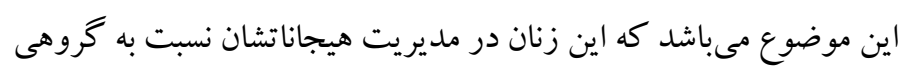

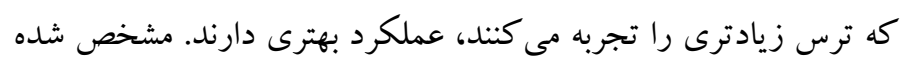

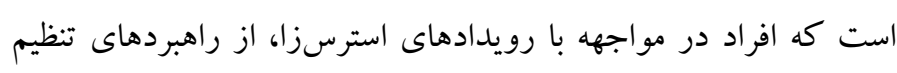

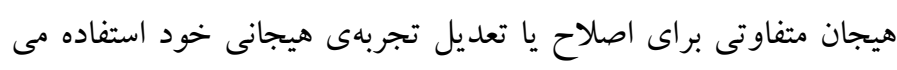

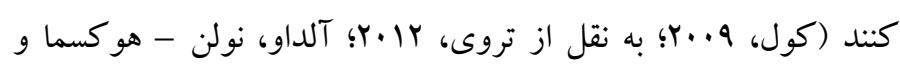

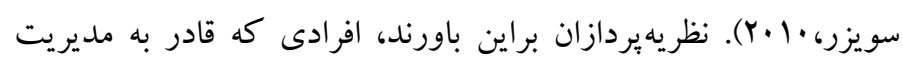

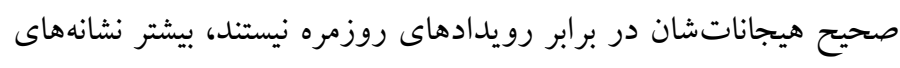
تشخيصى، اختلالهاى درونى نمود از قبيل افسردگى و اضطراب راب رانشان

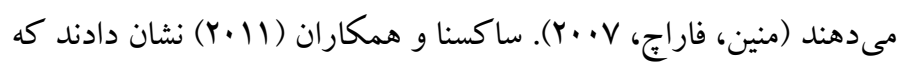

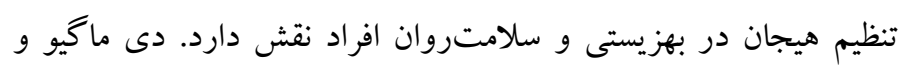
همكاران (Y.19) نيز رابطه سازكارى اجتماعى و تنظيم هيجان ران ران نشان

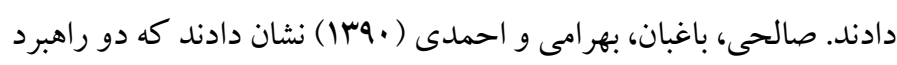

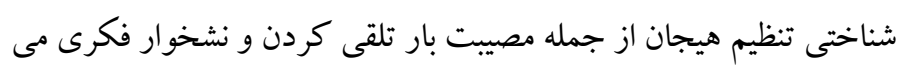

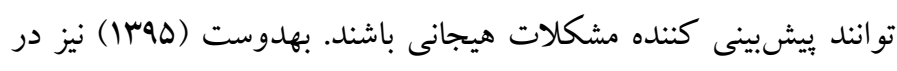
يزوهش خود نشان داد كه سبككهاى تنظيم هيجان در زنان خيانت ديده و زنان عادى با هم متفاوت مىباشد.

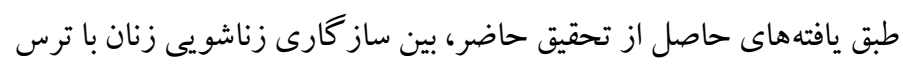

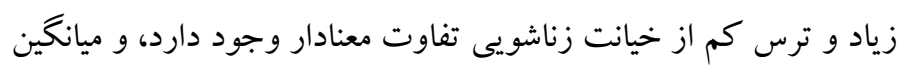

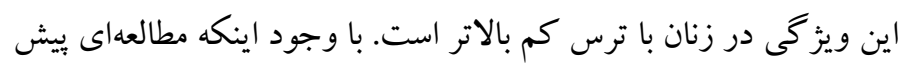

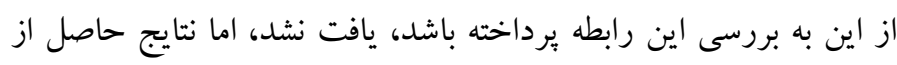

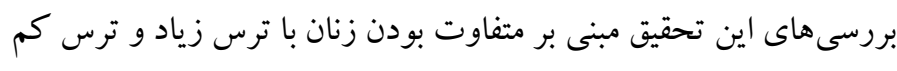

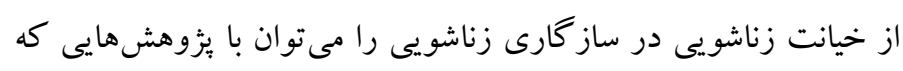




\section{References}

Aldao, A., Nolen-Hoeksema, S., \& Schweizer, S. (2010). Emotion-regulation strategies across psychopathology: A meta-analytic review. Clinical psychology review, 30(2), 217-237. [Link]

Ameri, F., Torabian, L., khodabakhsh, R. (2012). A comparative study of attachment dimensions and personality traits among unfaithful men and women who experienced infidelity and normal couple. Journal of Psychological Studies, 8(3), 9-26. [Link]

Aviram, I., \& Amichai-Hamburger, Y. (2005). Online infidelity: Aspects of dyadic satisfaction, selfdisclosure, and narcissism. Journal of ComputerMediated Communication, 10(3), JCMC1037. [Link]

Berger, K. A., Lynch, J., Prows, C. A., Siegel, R. M., \& Myers, M. F. (2013). Mothers' perceptions adults. Journal of Family Issues, 36, 212- 231. [Link]

Brown, EM, (2001). Patterns of infidelity and their treatment. New York, NY: Psychology Press. [Link]

Di Maggio, Rosanna, Carla Zappulla, Ugo Pace. (2016). The Relationship Between Emotion Knowledge, Emotion Regulation and Adjustment in Preschoolers: A Mediation Model. Journal Child Family Study. [Link]

Emsaki, G., Molavi, H, Chitsaz, A., Movahed Abtahi, M, Asgari, K. (2011). Psychometric Properties of the Montreal Cognitive Assessment (MoCA) in Parkinson's Disease Patients in Isfahan, Vol 29, No 158: 2nd week December:1606-1615.[Link]

Gross, J. J. (1998). The emerging field of emotion regulation: An integrative review. Review of General Psychology, 2, 271-299. [Link]

Jackson JB, Miller RB, Oka M, Henry RG. (2014). Gender differences in marital satisfaction: A meta-analysis. Journal of marriage and famil; 76(1):105-29. [Link]

Jafarzadeh Fadaki, S., Amani, P. (2015). Relationship of love and marital satisfaction with pornography among married university students in Birjand, Iran. Journal of Fundamentals of Mental Health, 17(5), 240-246.[Link]

James, J. (2014). Caffeine and cognitive performance: Persistent methodological challenges in caffeine research. Pharmacology Biochemistry and Behavior, 124, 117-122. [Link]

Javanmard, G., Mohammadi, R., Pourakbaran, E. (2016). The mediating role of the couples' mental health in mental health and marital satisfaction of each one.
Journal of Fundamentals of Mental Health, 18(4), 196-201. [Link]

Khodabakhshikoolaee, A., Bahrami, S., Rasstak H. (2017). The Quality of Love and Sexual Satisfaction Survey among Loyal and Unfaithful Married Men. Socialworkma; 5 (4):12-5.[Link]

Mark, p. k., Janssen, E \& Milhausen, R. (2011), Infidelity in Heterosexual Couples: Demographic, Interpersonal and Personality - Related Predictors of Extradyadic,Sex Center for Sexual Health Promotion, Arch sex behave, 40(5): 971-82. [Link]

Mehrabadi, S., Jahanian, S., Kazemnejad, A. (2017). Association of Depression and Anxiety with Cognitive Function in Patients with Polycystic Ovary Syndrome, J Mazandaran Univ Med Sci, 27 (147):159-170. [Link]

Mennin DS, Farach FJ. (2007). Emotion and evolving treatments for adult psychopathology, Clin Psychol Sci Practice, (14): 329-352. [Link]

Mohammadi, H., Mosavi, V. (2015). Comparison of Emotional Regulation and Self-Control in Children with and without Attention Deficit/Hyperactivity Disorder. J Child Ment Health; 2 (2):21-33. [Link]

Mutlu, B., Erkut, Z., Yıldırım, Z., \& Gündoğdu, N. (2018). A review on the relationship between marital adjustment and maternal attachment. Revista da Associação Médica Brasileira, 64(3), 243-252. [Link]

Peluso PR. (2013). Infidelity: A practitioner's guide to working with couples in crisis, New York: Rout ledge, 17-25. [Link]

Pornaghash Tehrani, S. S., Besharat, M. A, Abdoli, M. R, Feyzabadi, Z. (2009). Evaluation of the results of the "Newness" subscale of the 3D Personality Questionnaire (TPQ) in addicted and normal people. Journal of Psychological Sciences.8 (2), 336-346. [Link]

Rock PL, Roiser JP, Riede WJ, Blackwell AD. (2014). Cognitive impairment in depression:a systematic review and meta-analysis. Psychol Med. 44(10):2029-2040. [Link]

Salehi, A., Baghaban, I., Bahrani, F., Ahmadi, S. (2011). Relationships between Cognitive Emotion Regulations Strategies and Emotional Problems with regard to Personal and Familial Factors. $J$ of Family Counseling and Psychotherapy, 1(1), 1-19. [Link]

Saxena, Prachi., Dubey, Akanksha., \& Pandey, Rakesh. (2011). Role of Emotion Regulation Diffculties in Predicting Mental Health and Well-being. Journal 
Project Psychology \& Mental Health 18: 147-155. [Link]

Shackelford T, Besser A, Goetz AT. (2008). Personality, marital Satisfaction, and probability of marital infidelity. Individ Differ Res 6: 13-25. [Link]

Snyder, D. K., Castellani, A. M., \& Whisman, M. A. (2006). Current status and future directions in couple therapy. Annu. Rev. Psychol., 57, 317-344. [Link]

Spring JA \& Spring M, (1996). After the affair: Healing the pain and rebuilding trust when a partner has been unfaithful New York, NY: Harper Collins Publishers. [Link]

Teymori, Z., Pournaghash Tehrani, S. S. (2013). Relationship personality traits and marital adjustment in methadone maintained drug addicts and non addicts. Research in Clinical Psychology and Counseling, 3(1). [Link]

Verbaan, D., Marinus, J., Visser, M., van Rooden, S. M., Stiggelbout, A. M., Middelkoop, H. A., \& van Hilten, J. J. (2007). Cognitive impairment in Parkinson's disease. Journal of Neurology, Neurosurgery \& Psychiatry, 78(11), 1182-1187. [Link]

Zare, M., Rezaei, A. (2016). Mediating Role of the Cognitive Emotional Regulation for Personality Characters and Marital Satisfaction, 7(24), 91-102. [Link] 